Article

\title{
Preparation of Al-Containing ZSM-58 Zeolite Membranes Using Rapid Thermal Processing for $\mathrm{CO}_{2} / \mathrm{CH}_{4}$ Mixture Separation
}

\author{
Eiji Hayakawa and Shuji Himeno *
}

check for updates

Citation: Hayakawa, E.; Himeno, S. Preparation of Al-Containing ZSM-58 Zeolite Membranes Using Rapid Thermal Processing for $\mathrm{CO}_{2} / \mathrm{CH}_{4}$ Mixture Separation. Membranes 2021, 11, 623. https://doi.org/10.3390/ membranes 11080623

Academic Editor: Chong Yang Chuah

Received: 2 July 2021

Accepted: 11 August 2021

Published: 13 August 2021

Publisher's Note: MDPI stays neutral with regard to jurisdictional claims in published maps and institutional affiliations.

Copyright: (c) 2021 by the authors. Licensee MDPI, Basel, Switzerland. This article is an open access article distributed under the terms and conditions of the Creative Commons Attribution (CC BY) license (https:// creativecommons.org/licenses/by/ $4.0 /)$.
Department of Science of Technology Innovation, Nagaoka University of Technology, 1603-1, Kamitomioka-cho, Nagaoka, Niigata 940-2188, Japan; ehayakawa@chemeng.osakafu-u.ac.jp

* Correspondence: himeno@vos.nagaokaut.ac.jp; Tel./Fax: +81-258-479-623

Abstract: The synthesis of DDR-type zeolite membranes faces the problem of cracks that occur on the zeolite membrane due to differences in the thermal expansion coefficient between zeolite and the porous substrate during the detemplating process. In this study, Al-containing ZSM-58 zeolite membranes with DDR topology were prepared by rapid thermal processing (RTP), with the aim of developing a reproducible method for preparing DDR zeolite membrane without cracks. Moreover, we verified the influence of RTP before performing conventional thermal calcination (CTC) on ZSM-58 membranes with various silica-to-aluminum ( $\mathrm{Si} / \mathrm{Al}$ ) molar ratios. Using the developed method, an Al-containing ZSM-58 membrane without cracks was obtained, along with complete template removal by RTP, and it had higher $\mathrm{CO}_{2} / \mathrm{CH}_{4}$ selectivity. An all-silica ZSM- 58 membrane without cracks was obtained by only using the ozone detemplating method. ZSM- 58 crystals and membranes with various $\mathrm{Si} / \mathrm{Al}$ molar ratios were analyzed by using Fourier-transform infrared (FTIR) spectroscopy to confirm the effects of RTP treatment. Al-containing ZSM-58 zeolites had higher silanol concentrations than all-silica zeolites, confirming many silanol condensations by RTP. The condensation of silanol forms results in the formation of siloxane bonds and stronger resistance to thermal stress; therefore, RTP caused crack suppression in Al-containing ZSM-58 membranes. The results demonstrate that Al-containing ZSM-58 zeolite membranes with high $\mathrm{CO}_{2}$ permeance and $\mathrm{CO}_{2} / \mathrm{CH}_{4}$ selectivity and minimal cracking can be produced by using RTP.

Keywords: DDR; ZSM-58; rapid thermal processing; zeolite membrane; $\mathrm{CO}_{2}$ separation

\section{Introduction}

Zeolites have been investigated due to their unique crystal structures. They can be used in gas separation membranes, in which a porous substrate is covered by a thin zeolite layer. For example, DDR-type zeolites have pore sizes of $0.36 \mathrm{~nm} \times 0.44 \mathrm{~nm}$; therefore, their application as a membrane material has been studied for the separation of $\mathrm{CO}_{2}(0.33 \mathrm{~nm})$ from natural and digestive gases [1-8].

However, producing these membranes is challenging. Various phases might be generated from the target zeolite when the zeolite is synthesized on a porous substrate. Moreover, the production of many zeolites requires organic structure-directing agents (SDAs), which eventually need to be removed from the framework using high temperatures, which generates cracks due to differences in the thermal expansion coefficients between zeolite and the porous substrate $[9,10]$. The thermal expansion coefficients of DDR and the porous $\mathrm{Al}_{2} \mathrm{O}_{3}$ support are $+35.1 \times 10^{-6} / \mathrm{K}(298-492 \mathrm{~K})$ to $-8.7 \times 10^{-6} / \mathrm{K}(492-1185 \mathrm{~K})$ and $\sim 7.5 \times 10^{-6} / \mathrm{K}$, respectively [1,11]. In fact, some researchers have reported that cracks form on DDR-type zeolite membranes during high-temperature calcination [1,2]. Therefore, inhibiting the occurrence of cracks to obtain membranes with a high gas separation performance is necessary. 
Possible approaches in suppressing crack formation include the ozone detemplate method and rapid thermal processing (RTP). The ozone detemplate method can remove SDAs at lower temperatures than the conventional thermal detemplate method. The ozone detemplate method has been applied not only to DDR-type zeolite (DD3R, ZSM-58) membranes but also to other zeolite membranes [1,3,4,8,12,13].

RTP is a preprocessing method in which the zeolite membrane is rapidly heated and then cooled, and cracks can be suppressed during high-temperature calcination by increasing the bonding strength among zeolites during this process. RTP has been applied to some membranes, such as CHA and MFI [12-18]. However, Wang et al. reported that RTP did not affect DD3R zeolite membranes because of the low concentration of surface silanols in all-silica zeolite [1]. On the other hand, ZSM-58 has the DDR topology of Alcontaining zeolites and is reported to have a Si / Al molar ratio of $20-\infty$ [19]. Therefore, we speculated that RTP treatment would result in crack suppression of Al-containing DDRtype zeolite membranes due to the concentration of silanol in the zeolite increasing with the Al concentration [20], and ZSM-58 zeolite has DDR topology. Recently, we reported that all-silica ZSM-58 zeolites can be used to afford high-purity DDR-type zeolite membranes with $\mathrm{CO}_{2} / \mathrm{CH}_{4}$ and $\mathrm{CO}_{2} / \mathrm{N}_{2}$ separation performances equivalent to those previously reported for DD3R membranes [4]. In this study, we examined the synthesis conditions of Al-containing ZSM-58 zeolite membranes as well as the effect of RTP treatment on ZSM-58 membranes with various $\mathrm{Si} / \mathrm{Al}$ molar ratios. We compared the all-silica and Al-containing ZSM-58 membranes prepared by using different detemplate methods in terms of their performance in $\mathrm{CO}_{2} / \mathrm{CH}_{4}$ gas mixture separation. Moreover, the effect of RTP treatment was confirmed by observing changes in the silanol concentration of ZSM- 58 zeolite crystals and membranes at various calcination conditions by using Fourier-transform infrared (FTIR) spectroscopy.

\section{Experimental Procedure}

\subsection{Materials}

The following chemicals and materials were used: Ludox HS-30 colloidal silica (30 wt.\%, Sigma-Aldrich, St. Louis, MO, USA), sodium hydroxide (97.0\%, Wako, Osaka, Japan), potassium hydroxide $(85 \%$, Wako), sodium aluminate $(\mathrm{Al} / \mathrm{NaOH}$ molar ratio $=0.77$, Wako, Osaka, Japan), tropine (98\%, Combi-Blocks, San Diego, CA, USA), methyl iodide (99.5\%, Wako), and ethanol (99.5\%, Wako, Osaka, Japan). In addition, $\mathrm{CO}_{2}(99 \%)$ and $\mathrm{CH}_{4}(99 \%)$ were used for the gas permeation test. The alumina support used was the same as in our previous study [4]. The alumina support was composed of the surface, middle, and support layers; zeolite crystals were mainly synthesized on the surface layer. ZSM-58 zeolite membranes were prepared on the outside surface of porous $\alpha$-alumina tubes (porosity, 30-50\%; outer diameter, $9.6 \mathrm{~mm}$; inner diameter, $7.2 \mathrm{~mm}$; length, $3 \mathrm{~cm}$; NGK Insulators, Ltd., Nagoya, Japan). The thicknesses of the surface, middle, and support layers in the alumina support were 50,100, and $1050 \mu \mathrm{m}$, respectively. Moreover, the pore diameters of the surface, middle, and support layers in the alumina support were 0.2, 0.9, and $2-10 \mu \mathrm{m}$, respectively.

\subsection{Preparation of Methyltropinium Iodide (MTI) as a Structure-Directing Agent}

Methyltropinium iodide (MTI) was used as the structure-directing agent (SDA) in the synthesis of ZSM-58 zeolite. MTI was prepared following the protocol reported in our previous study [4]. For the synthesis of MTI, $25.0 \mathrm{~g}$ tropine was first dissolved in $100 \mathrm{~g}$ ethanol. Next, $25.1 \mathrm{~g}$ methyl iodide was added to the solution, and the suspension was maintained under reflux for $72 \mathrm{~h}$. After cooling, the as-made MTI was washed with ethanol and dried at $343 \mathrm{~K}$.

\subsection{Synthesis of ZSM-58 Seed Crystals for Membrane Preparation}

The ZSM-58 seed crystals were prepared following the protocol reported in our previous study [4]. For the synthesis of ZSM-58 seed crystals, a precursor solution with a 
composition molar ratio of MTI:NaOH:SiO $2: \mathrm{H}_{2} \mathrm{O}=0.25: 0.33: 1: 40$ was used. The precursor solution was prepared as follows: $6.4 \mathrm{~g}$ MTI was added to $42.9 \mathrm{~g} \mathrm{H}_{2} \mathrm{O}$ (solution A); $9.97 \mathrm{~mL}$ $3 \mathrm{M} \mathrm{NaOH}$ and $18.2 \mathrm{~g}$ Ludox HS-30 were then added to solution A and stirred for $24 \mathrm{~h}$ (solution B). Solution B was then transferred into a Teflon-lined autoclave and maintained at $433 \mathrm{~K}$ for $72 \mathrm{~h}$ under rotational stirring. The as-synthesized ZSM- 58 zeolite seed crystals were washed with DI water. After drying at $343 \mathrm{~K}$ overnight, ZSM-58 seed crystals were calcined at $973 \mathrm{~K}$ for $4 \mathrm{~h}$ at a ramp rate of $0.5 \mathrm{~K} / \mathrm{min}$ under atmosphere. Figure 1 shows the SEM image and XRD profile of ZSM-58 seed crystals after calcination.
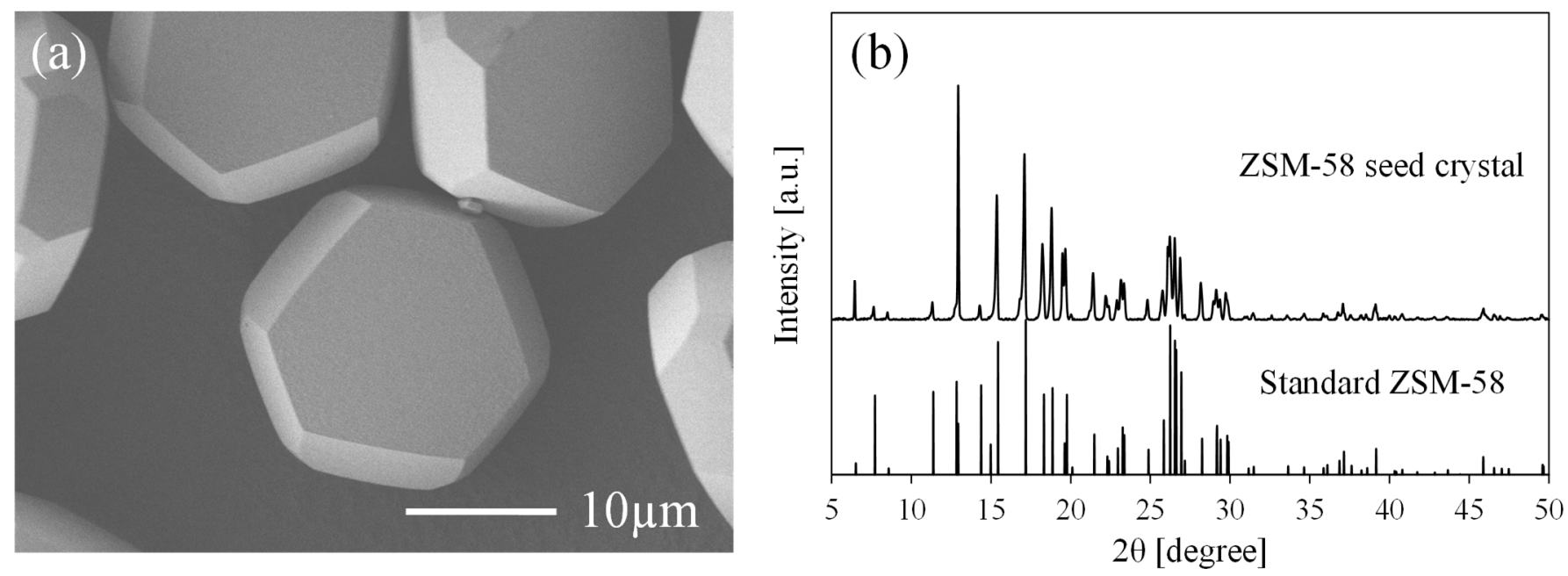

Figure 1. (a) SEM image and (b) XRD profile of ZSM-58 seed crystals used in this study.

The calcined ZSM-58 zeolite particles were then milled, and the ball-milled particles were dispersed in deionized (DI) water. Consequently, a ZSM-58 seed slurry with a particle size distribution of $0.2 \mu \mathrm{m}$ was prepared by using a centrifugation method.

\subsection{Preparation of Al-Containing ZSM-58 Crystals to Determine Optimal Conditions for Membrane Synthesis}

The ZSM-58 zeolite crystal was prepared under various conditions in order to determine the optimal conditions for synthesis of Al-containing ZSM-58 zeolite membranes.

The precursor gel of ZSM-58 crystals (C1-8) was prepared as follows: MTI, an alkali source $(\mathrm{NaOH}$ or $\mathrm{KOH})$, and sodium aluminate were added to DI water (solution $\mathrm{A}$ ). Ludox HS-30 colloidal silica and the alkali source were also added to DI water (solution B). The precursor gel of ZSM-58 crystals was obtained by mixing and stirring solutions A and $\mathrm{B}$ for $24 \mathrm{~h}$ at room temperature. The gel composition of all samples had a $\mathrm{Si} / \mathrm{Al}$ molar ratio of 70 and $\mathrm{H}_{2} \mathrm{O} / \mathrm{SiO}_{2}$ molar ratio of 52. Moreover, ZSM-58 crystals were prepared with molar ratios of $\mathrm{MTI} / \mathrm{SiO}_{2}$ and $\mathrm{MeOH} / \mathrm{SiO}_{2}$ from 0.05 to 0.3 .

Next, 0.1 wt. \% of ZSM-58 seed crystals was added to the precursor gel. Then, the precursor gel was transferred to a Teflon-lined autoclave, and hydrothermal treatment was conducted at a constant temperature (413 or $423 \mathrm{~K}$ ) and time (24-192 h). After the hydrothermal treatment, the Teflon-lined autoclave was quickly cooled using water. The as-made crystals were washed with ethanol and DI water by filtration cleaning and dried overnight at $343 \mathrm{~K}$. The as-made crystals were washed with DI water and dried at $343 \mathrm{~K}$ overnight. Finally, the ZSM-58 zeolite crystals were calcined at $823 \mathrm{~K}$ for $4 \mathrm{~h}$ at a ramp rate of $0.5 \mathrm{~K} / \mathrm{min}$ under a standard atmosphere.

\subsection{Preparation of ZSM-58 Zeolite Membranes}

ZSM-58 zeolite membranes were prepared on $\alpha$-alumina tubular with the secondary growth method. Ball-milled ZSM-58 seed particulates were coated on the outermost surface layer of the alumina tubular support using a dip-coating method with ZSM-58 seed slurry. 
The precursor gel for the Al-containing ZSM-58 membrane (M1-4) was prepared by using the method described in Section 2.4. The Al-containing ZSM-58 membranes were prepared from a gel composition of MTI:KOH:SiO $2: \mathrm{H}_{2} \mathrm{O}=0.05: 0.05: 1: 52$ at $413 \mathrm{~K}$ for the requisite synthesis time. All-silica ZSM-58 membranes (M5 and M6) were prepared from a gel composition of MTI:KOH:SiO $2: \mathrm{H}_{2} \mathrm{O}=0.1: 0.1: 1: 52$ at $413 \mathrm{~K}$ for $48 \mathrm{~h}$, based on our previous report which investigated the influence of the membrane $\mathrm{Si} / \mathrm{Al}$ molar ratio on RTP [4]. Please note that $\mathrm{KOH}$ was used for the synthesis of all-silica ZSM-58 membranes to mitigate the influence of the alkali source, unlike in our previous procedure. $\alpha$-Alumina tubular support-coated ZSM-58 seed crystals were placed vertically in a Teflonlined autoclave. A precursor gel was then transferred into the Teflon-lined autoclave, and hydrothermal treatment was conducted. Subsequently, the as-made membrane was washed with boiling water and dried overnight at $343 \mathrm{~K}$.

\subsection{Calcination of ZSM-58 Zeolite Membranes}

The as-made ZSM-58 membranes were calcined using the conventional thermal calcination (CTC) method or ozone detemplate method. For some membranes, RTP was applied prior to the CTC method.

Figure 2 shows the temperature program of the RTP and CTC process. RTP has been reported in other zeolite membranes, such as MFI and CHA-type zeolites [12-18], and RTP treatment conditions were selected based on those reports. The membrane was directly loaded into a preheated muffle furnace at $973 \mathrm{~K}$ for $1 \mathrm{~min}$ and then quickly removed and cooled to room temperature under flowing air. Then, the CTC method was performed in which the membrane was heated at $823 \mathrm{~K}$ for $4 \mathrm{~h}$ at a heating and cooling rate of $0.5 \mathrm{~K} / \mathrm{min}$ in a muffle furnace atmosphere.

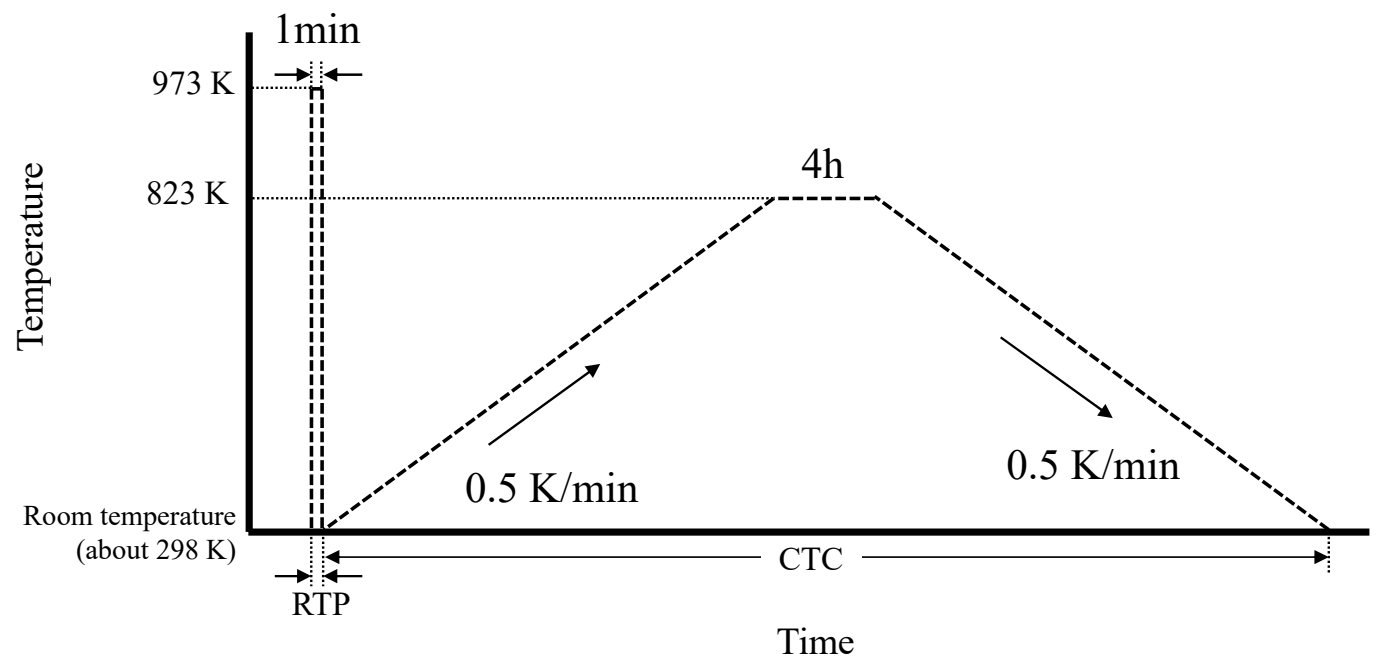

Figure 2. Temperature program of RTP and CTC.

The calcination conditions of the ozone detemplate method (ozone) were obtained from the literature $[3,4,8,12,13]$. Figure 3 shows the ozone detemplate apparatus. The ozone mixture was generated from oxygen gas. The zeolite layer was synthesized on the outer surface of the alumina tubular support, this zeolite surface layer was exposed to the oxygen-ozone gas mixture $\left(\mathrm{O}_{2}+\mathrm{O}_{3}\right)$ the. The membrane was placed on a membrane module in contact with ozone at a concentration of $120 \mathrm{~g} / \mathrm{Nm}^{3}$ and a flow rate of $1 \mathrm{~L} / \mathrm{min}$ (about $110 \mathrm{~mL} / \mathrm{min} / \mathrm{cm}^{2}$ ) at $473 \mathrm{~K}$ for $48 \mathrm{~h}$. 


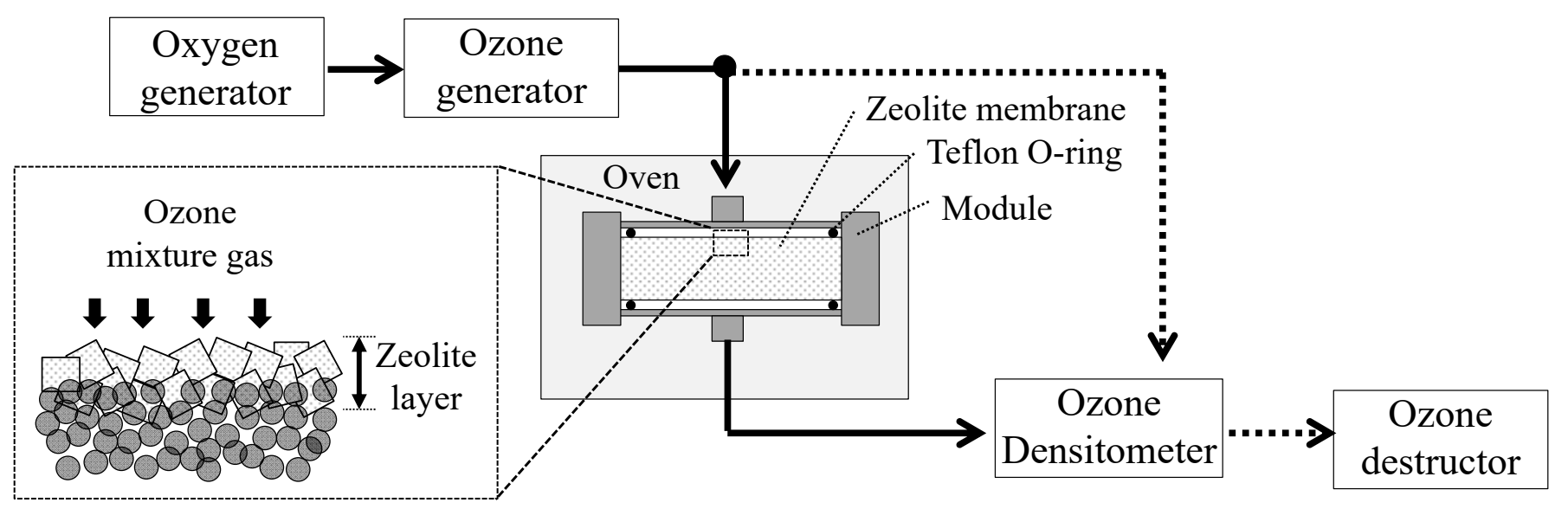

Figure 3. Schematic of the ozone detemplate apparatus.

\subsection{Gas Permeation and Separation Measurements}

The pure $\mathrm{CH}_{4}$ gas permeance was measured for the noncalcined ZSM-58 zeolite membrane in order to evaluate its denseness immediately after hydrothermal synthesis; the feed pressure was $1.1 \mathrm{MPa}$.

Moreover, an equimolar $\mathrm{CO}_{2} / \mathrm{CH}_{4}$ mixture, prepared by blending pure $\mathrm{CO}_{2}$ and $\mathrm{CH}_{4}$ gas, was used to evaluate the permeance characteristics of ZSM-58 zeolite membranes. The membrane was dried at $423 \mathrm{~K}$ prior to the permeation test. The total feed pressure of the $\mathrm{CO}_{2} / \mathrm{CH}_{4}$ mixture gas was $1.1 \mathrm{MPa}$, and the permeate pressure was atmospheric pressure (about $0.1013 \mathrm{MPa}$ ). The gas permeation temperature was maintained at $298 \mathrm{~K}$, and the gas flux and concentration were determined with a soap film flowmeter and a gas chromatograph (490 Micro GC, GL Science, Tokyo, Japan), respectively. The permeation test was conducted by using a membrane that had dried under dry gas flow at $383 \mathrm{~K}$.

The permeance, $P_{i}\left(\mathrm{~mol} / \mathrm{s} / \mathrm{m}^{2} / \mathrm{Pa}\right)$, was calculated using the following formula:

$$
P_{i}=\frac{Q_{i}}{A \cdot t \cdot \Delta p_{i}}
$$

where $Q_{i}(\mathrm{~mol})$ is the mole of component $i$ permeated through the membrane for $t(\mathrm{~s})$, $A\left(\mathrm{~m}^{2}\right)$ is the membrane area, and $\Delta p i(\mathrm{~Pa})$ is the differential partial pressure of component $i$ between the feed and permeate side. The $\mathrm{CO}_{2} / \mathrm{CH}_{4}$ separation selectivity $\left(\mathrm{PCO}_{2} / \mathrm{PCH}_{4}\right)$ was the permeance ratio of the mixture and gas. The feed rate of the $\mathrm{CO}_{2} / \mathrm{CH}_{4}$ mixture was $1 \mathrm{~L} \mathrm{~min}{ }^{-1}$, and the differences in gas concentrations between the feed and retentate sides were less than $1.0 \%$. Therefore, we discounted the effect of concentration polarization in the gas mixture on $\mathrm{CO}_{2} / \mathrm{CH}_{4}$ selectivity.

\subsection{Characterization}

Nitrogen adsorption isotherms were measured at $77 \mathrm{~K}$ and with BELSORP-max apparatus (MicrotracBEL Corp, Osaka, Japan). The XRD (XRD-6100, Shimadzu, Kyoto, Japan) profiles were recorded by using $\mathrm{Cu}-\mathrm{K} \alpha$ radiation. The SEM images were obtained on a field emission SEM (JSM-6701, JEOL Ltd., Tokyo, Japan) operated at an accelerating voltage of $1 \mathrm{kV}$ and a work distance of 8-11 $\mathrm{mm}$. Element mapping and line analysis were performed using energy-dispersive X-ray spectrometry (EDS). Elemental analysis of the ZSM-58 zeolite crystals was conducted by using X-ray fluorescence spectroscopy (XRF; Rigaku ZSX Primus II, Rigaku Co., Tokyo, Japan). FTIR spectroscopy was measured by JASCO FT/IR-4100(JASCO Corporation, Tokyo, Japan), and the FTIR spectra of ZSM-58 crystals and membranes were obtained by attenuated total reflectance (ATR) by using ATR PRO ONE attached to a ZnSe prism (JASCO Corporation, Tokyo, Japan). 


\section{Results and Discussion}

\subsection{Si/Al Molar Ratios and Crystallization Rates of ZSM-58 Crystals at Various Gel Compositions}

Initially, the effects of the alkali source and gel composition on ZSM-58 crystals were investigated in order to determine the synthesis conditions for Al-containing ZSM-58 zeolite membranes. Table 1 shows the Si / Al molar ratios of ZSM- 58 crystals by XRF with different gel compositions. All samples were synthesized for $2 \mathrm{~d}$ at $423 \mathrm{~K}$. Compared with $\mathrm{NaOH}, \mathrm{KOH}$ produced ZSM-58 crystals with a lower Si/Al molar ratio due to the high dissolution ability of the aluminosilicate [21]. In addition, the high $\mathrm{MeOH} / \mathrm{SiO}_{2} \mathrm{molar}$ ratio induced a low $\mathrm{Si} / \mathrm{Al}$ molar ratio. Thus, $\mathrm{KOH}$ is the most suitable alkali to efficiently load Al into zeolites.

Table 1. Si / Al molar ratios of ZSM-58 crystals at various gel compositions at $423 \mathrm{~K}$ for $24 \mathrm{~h}$.

\begin{tabular}{|c|c|c|c|c|c|c|}
\hline \multirow{2}{*}{ Crystal No. } & \multicolumn{4}{|c|}{ Gel Molar Ratio } & \multirow{2}{*}{ Me Source * } & \multirow{2}{*}{$\begin{array}{c}\text { Measurement } \\
\text { of Si/Al with } \\
\text { XRF }\end{array}$} \\
\hline & $\mathrm{MTI} / \mathrm{SiO}_{2}$ & $\mathrm{MeOH} / \mathrm{SiO}_{2}$ & Si/Al & $\mathrm{H}_{2} \mathrm{O} / \mathrm{SiO}_{2}$ & & \\
\hline $\mathrm{C} 1$ & 0.05 & 0.05 & \multirow{4}{*}{70} & \multirow{4}{*}{52} & \multirow{4}{*}{$\mathrm{NaOH}$} & 116 \\
\hline $\mathrm{C} 2$ & 0.1 & 0.1 & & & & 112 \\
\hline $\mathrm{C} 3$ & 0.1 & 0.3 & & & & 82 \\
\hline $\mathrm{C} 4$ & 0.3 & 0.1 & & & & 91 \\
\hline C5 & 0.05 & 0.05 & \multirow{4}{*}{70} & \multirow{4}{*}{52} & \multirow{4}{*}{$\mathrm{KOH}$} & 79 \\
\hline C6 & 0.1 & 0.1 & & & & 72 \\
\hline $\mathrm{C} 7$ & 0.1 & 0.3 & & & & 52 \\
\hline $\mathrm{C} 8$ & 0.3 & 0.1 & & & & 73 \\
\hline
\end{tabular}

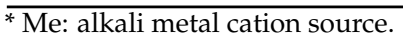

Subsequently, the crystallization rate of different gel compositions was compared with the rates observed when $\mathrm{KOH}$ was used as the Me source. Figure 4 shows the weight ratios of ZSM-58 to raw silica with different synthesis times. Figure 5 shows the XRD peaks of the as-fabricated C5-C8 crystals with various synthesis periods. The crystallization rate was high at a temperature of $423 \mathrm{~K}$; therefore, this experiment was conducted at $413 \mathrm{~K}$. After $2 \mathrm{~d}$, C5 did not form a ZSM-58 zeolite and neither did C6-C8 after $1 \mathrm{~d}$, as evidenced by XRD. Thus, the amount of synthesized ZSM-58 was taken as $0 \mathrm{~g}$. The prepared powders obtained after longer synthesis times had high purity and crystallinity, confirmed from the XRD profiles (Figure 5); therefore, we assumed that the amount of synthesized ZSM-58 was the same as the weight of the as-prepared powder. For compositions C6-C8, the ZSM-58 zeolite rapidly crystallized within $24-48 \mathrm{~h}$. By contrast, the ratio of the zeolite to raw silica increased with the synthesis time under $C 5$ conditions for $48 \mathrm{~h}$, suggesting that the rate of crystal nucleation under C5 conditions was slower. Slow crystal nucleation was observed in low MTI and $\mathrm{SiO}_{2}$ concentration; thus, these were assumed to be good crystal growth conditions. When synthesizing a dense zeolite membrane, the grain boundaries must be filled by growing seed crystals in a porous $\alpha$-alumina support; therefore, it was concluded that the conditions for $\mathrm{C} 5$ are the most suitable of those tested for synthesizing Al-containing ZSM-58 zeolite membranes. 


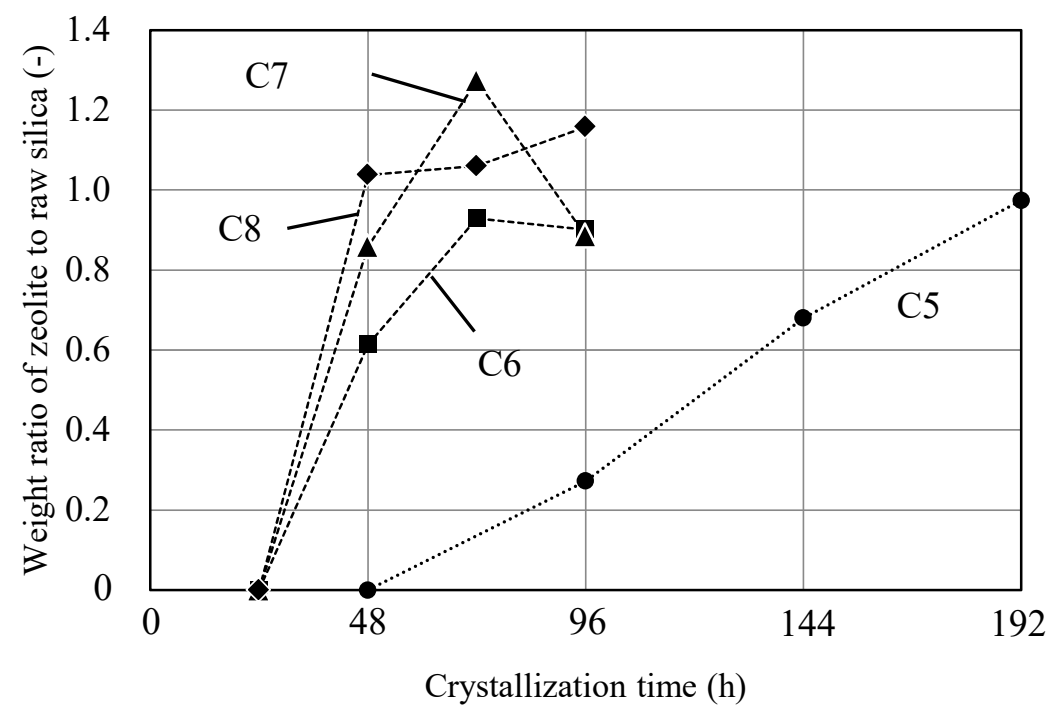

Figure 4. Weight ratio of zeolite to raw silica for gel compositions C5-C8 at $413 \mathrm{~K}$.

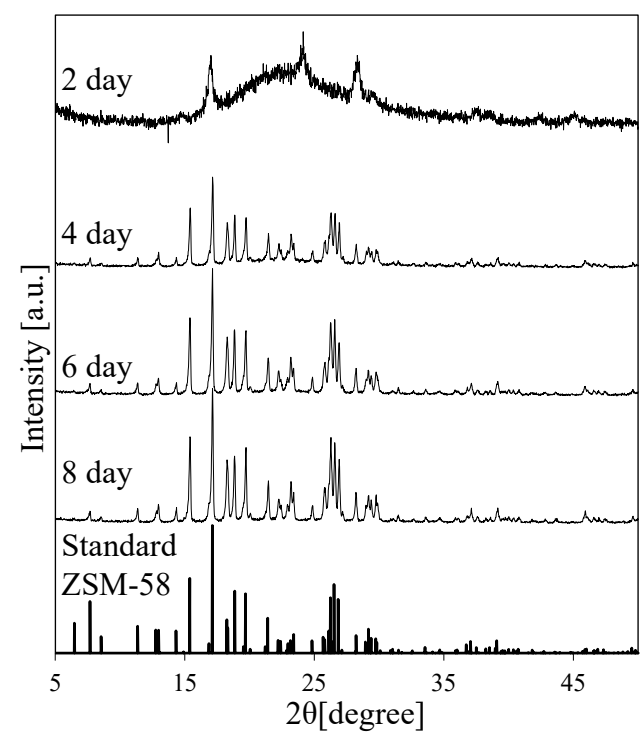

(a) C5

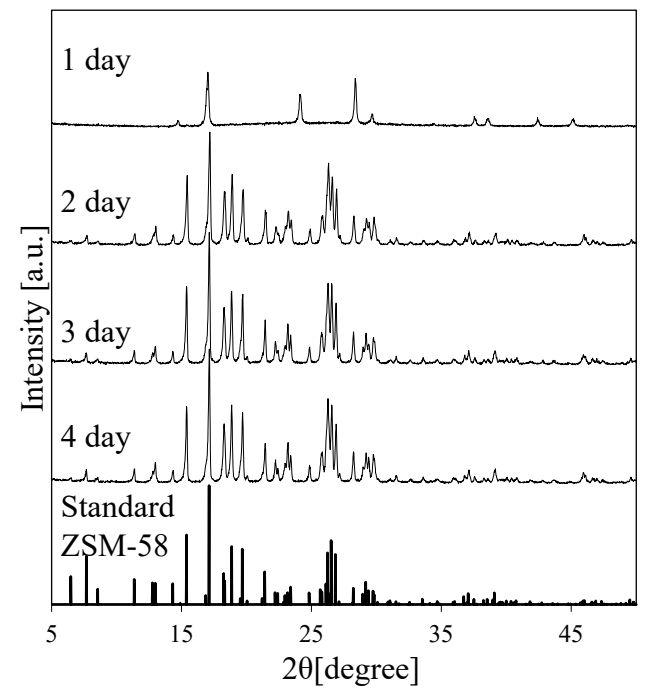

(c) $\mathrm{C} 7$

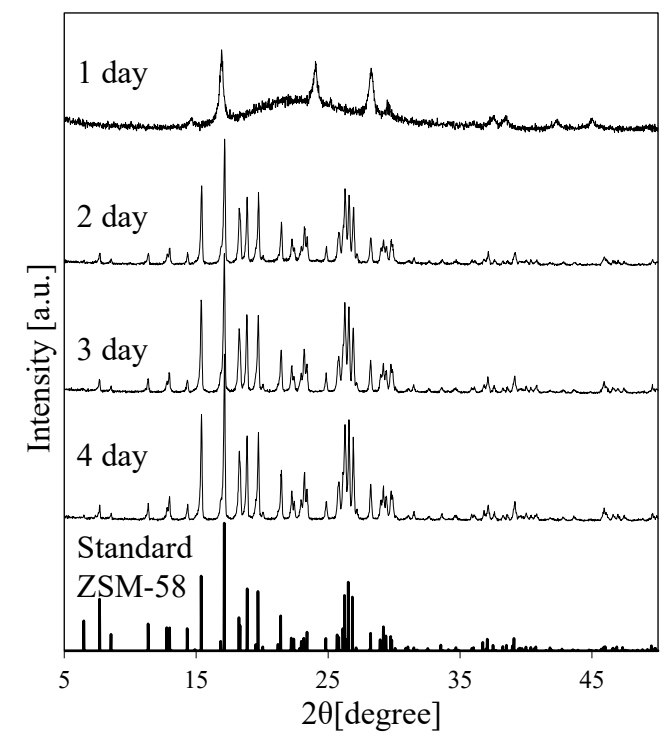

(b) C6

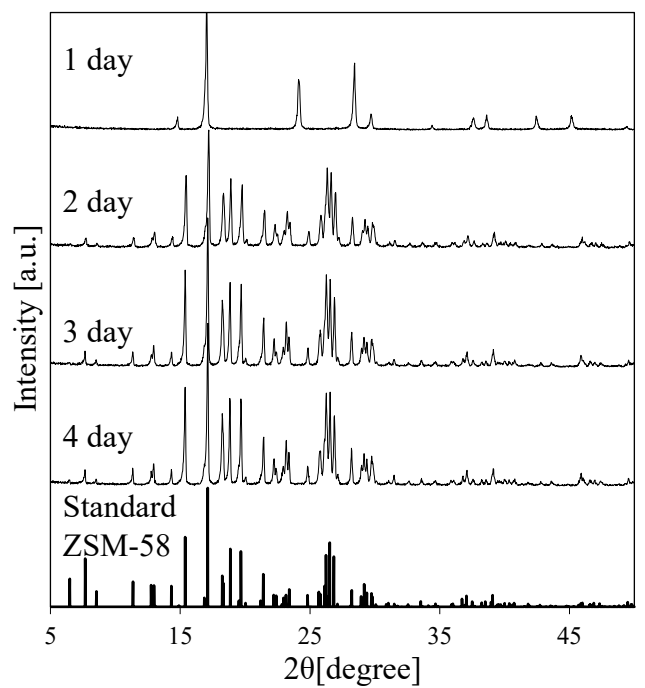

(d) $\mathrm{C} 8$

Figure 5. XRD profiles of the as-made crystals with various synthesis periods and gel compositions of (a) C5, (b) C6, (c) C7 and (d) $\mathrm{C} 8$ at $413 \mathrm{~K}$. 


\subsection{Influence of Synthesis Time on Al-Containing ZSM-58 Membranes}

As shown in Table 2, the influence of the synthesis time on the separation performance of Al-containing ZSM-58 zeolite membranes was monitored by using composition C5 at $413 \mathrm{~K}$. M1-M4 membranes were calcined via the CTC method, and RTP was applied prior to CTC. Figures 6 and 7 show the XRD profiles and SEM images of the surfaces and cross-sections of M1-M4, respectively. Figure 8 shows the $\mathrm{CO}_{2}$ permeance and $\mathrm{CO}_{2} / \mathrm{CH}_{4}$ selectivity of Al-containing ZSM-58 membranes as functions of synthesis time; each value are the averages of two samples prepared by same synthesis condition. The maximum error of $\mathrm{CO}_{2}$ permeance between the two samples is $1.0 \times 10^{-8} \mathrm{~mol} / \mathrm{m}^{2} / \mathrm{s} / \mathrm{Pa}$.

Table 2. Equimolar $\mathrm{CO}_{2} / \mathrm{CH}_{4}$ mixture separation performances of Al-containing ZSM-58 zeolite membranes with different synthesis times at a total feed pressure of $1.1 \mathrm{MPa}$ and at room temperature.

\begin{tabular}{|c|c|c|c|c|c|c|}
\hline \multirow{2}{*}{ No. } & \multirow{2}{*}{$\begin{array}{l}\text { Synthesis } \\
\text { Time (h) }\end{array}$} & \multirow{2}{*}{ Thickness( $\mu \mathrm{m})$} & \multirow{2}{*}{$\begin{array}{l}\mathrm{CH}_{4} \text { Permeance of the } \\
\text { Noncalcined Membrane } \\
\left(\times 10^{-10} \mathrm{~mol} / \mathrm{m}^{2} / \mathrm{s} / \mathrm{Pa}\right)\end{array}$} & \multicolumn{2}{|c|}{ Permeance $\left(\mathrm{mol} / \mathrm{m}^{2} / \mathrm{s} / \mathrm{Pa}\right)$} & \multirow{2}{*}{$\begin{array}{c}\mathrm{CO}_{2} / \mathrm{CH}_{4} \\
\text { Selectivity }\end{array}$} \\
\hline & & & & $\times 10^{-8} \mathrm{PCO}_{2}$ & $\times 10^{-10} \mathrm{PCH}_{4}$ & \\
\hline M1 & 72 & 4.1 & 3.1 & 11 & 87 & 13 \\
\hline M2 & 84 & 8.5 & 1.8 & 8.5 & 29 & 29 \\
\hline M3 & 96 & 12 & 0.8 & 6.1 & 13 & 45 \\
\hline M4 & 120 & 8.0 & $<0.1$ & 7.8 & 5.3 & 150 \\
\hline
\end{tabular}

${ }^{*} \mathrm{CH}_{4}$ leak permeance was measured before calcination.

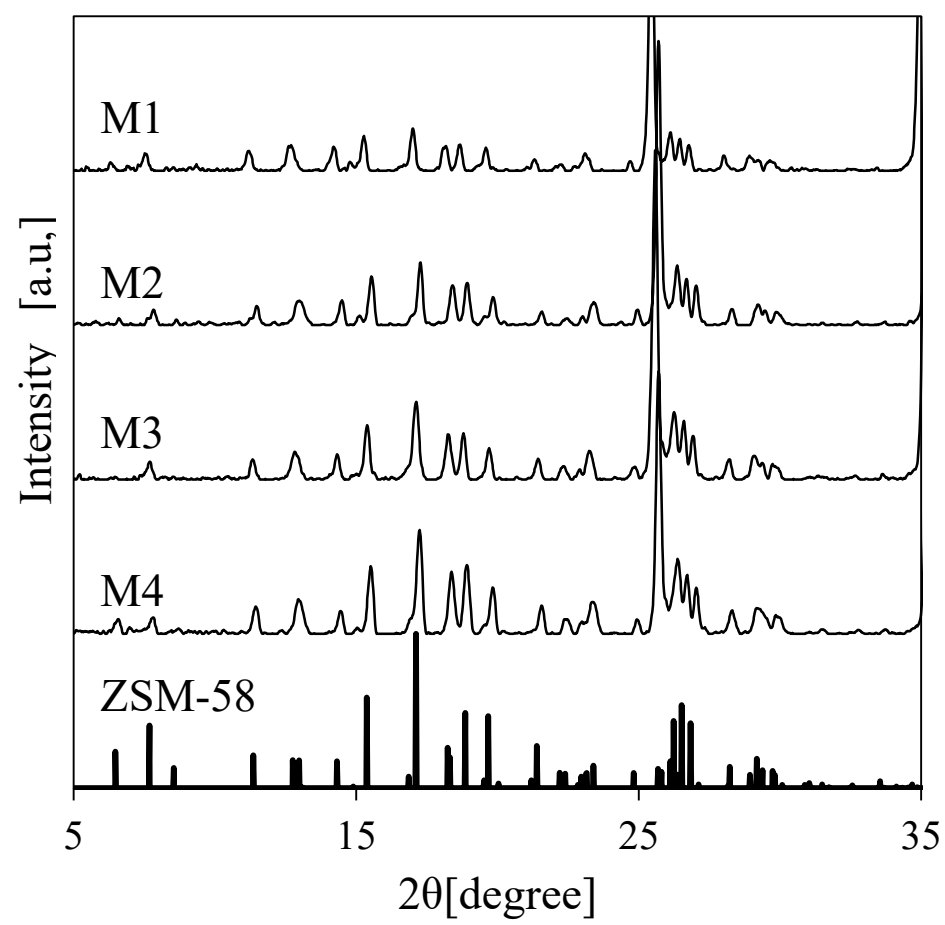

Figure 6. XRD profile of ZSM-58 zeolite membranes using various synthesis periods. 

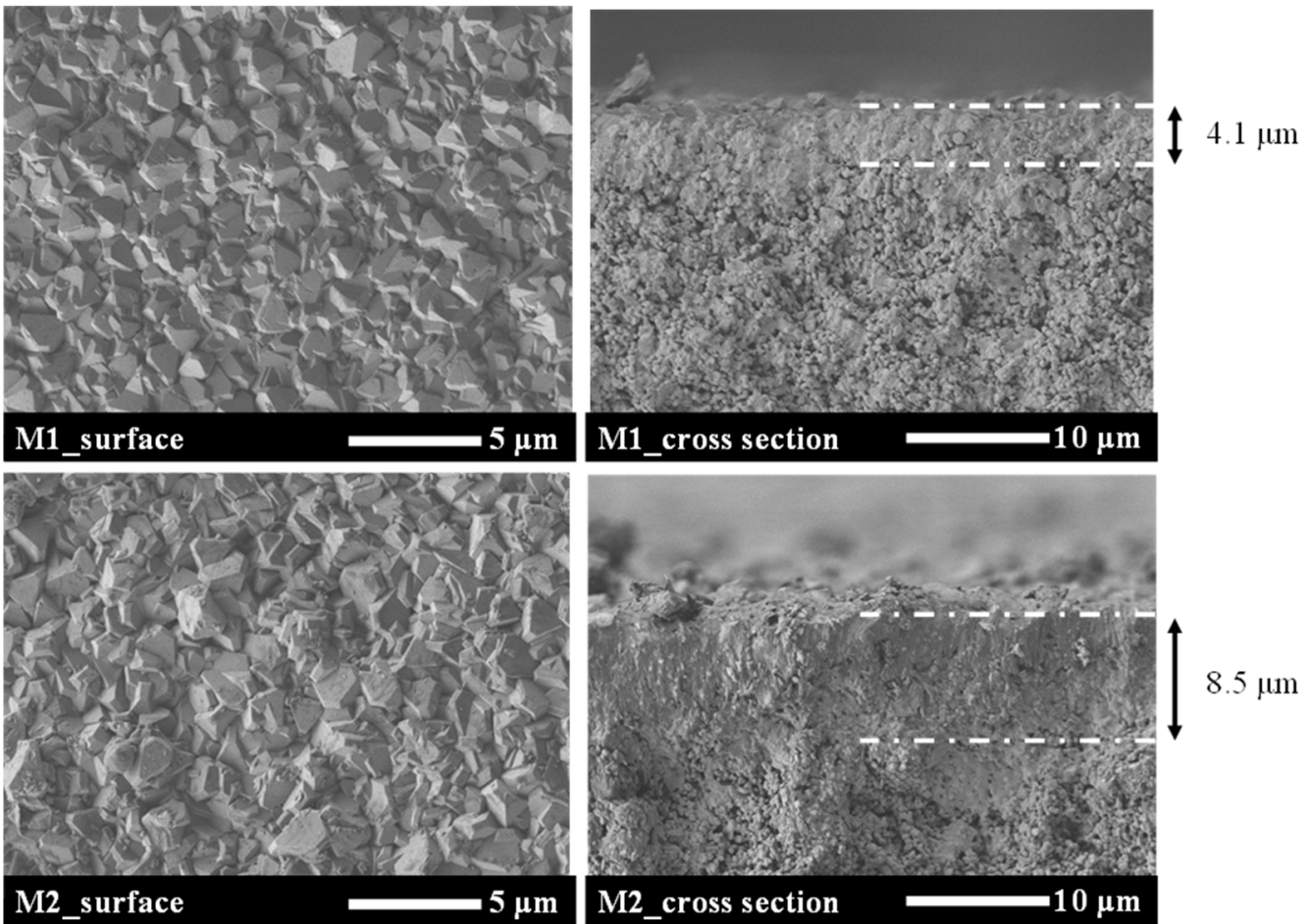

M2_surface

$5 \mu \mathrm{m}$
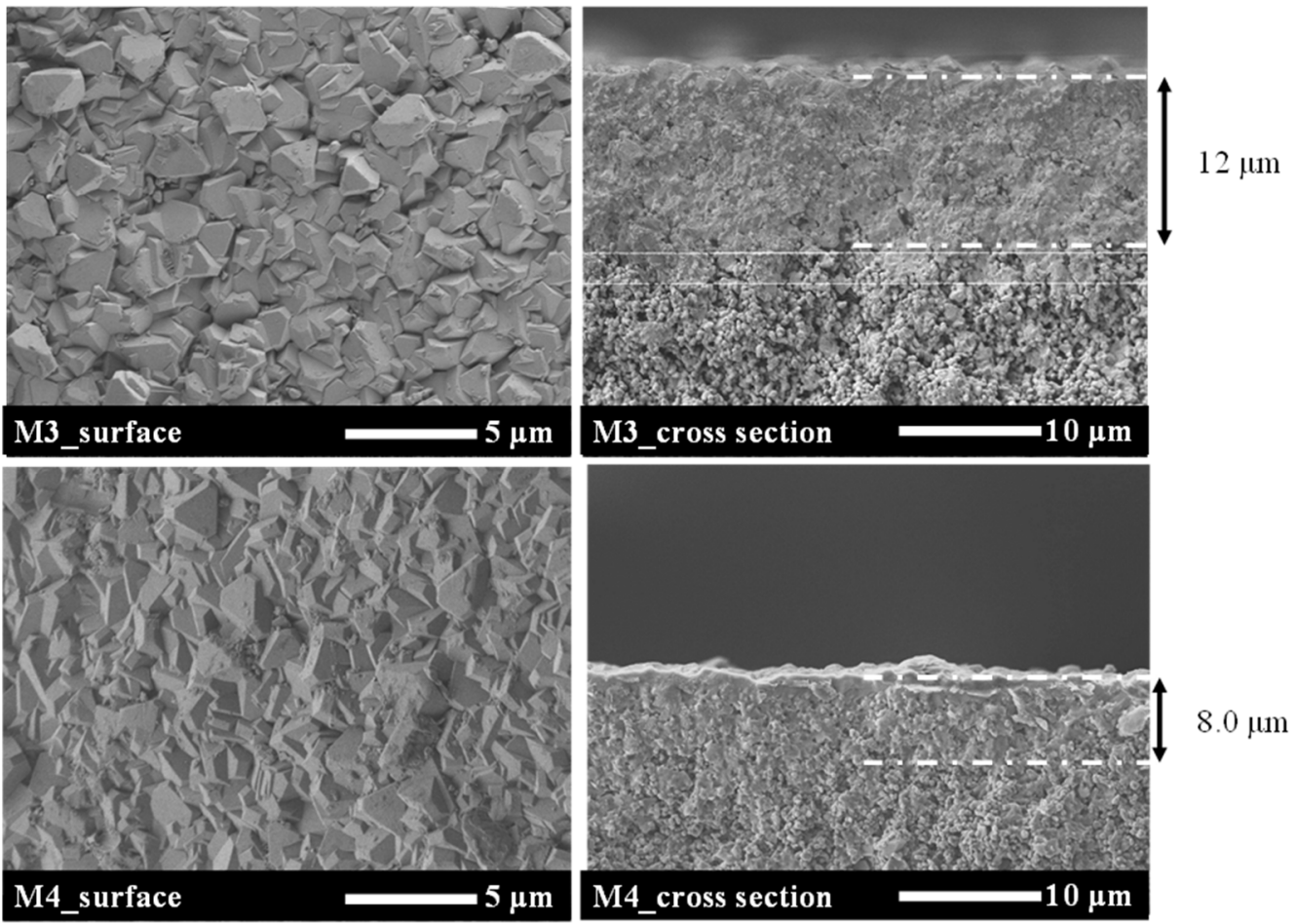

M4_surface $5 \mu \mathrm{m}$

M4 cross section

$10 \mu \mathrm{m}$

Figure 7. SEM images of the surfaces and cross-sections of Al-containing ZSM-58 zeolite membranes synthesized for various periods. The arrows denote the membrane thickness. 


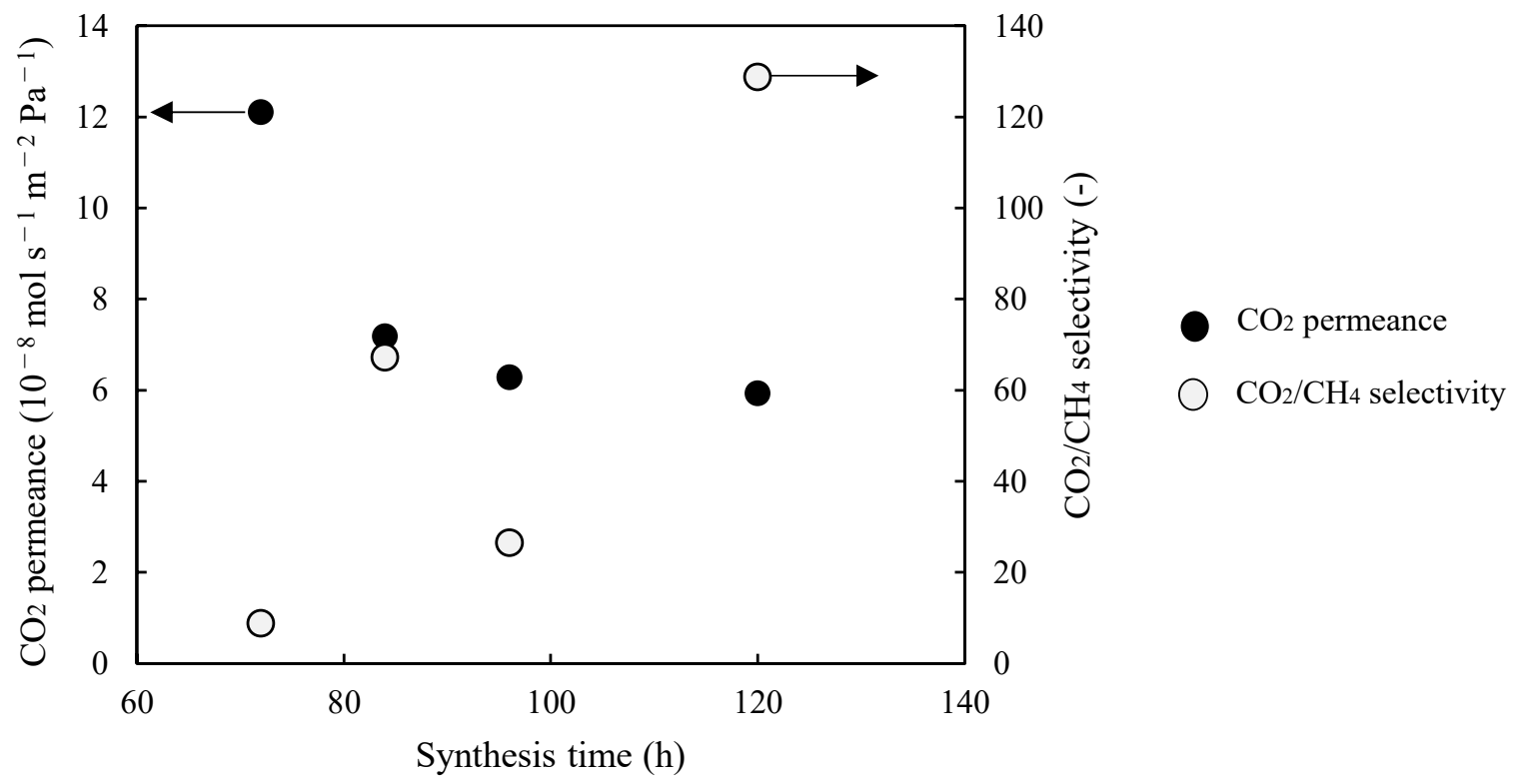

Figure 8. $\mathrm{CO}_{2}$ permeance and $\mathrm{CO}_{2} / \mathrm{CH}_{4}$ selectivity of Al-containing ZSM-58 membranes as functions of synthesis time. $\mathrm{CO}_{2}$ permeance and $\mathrm{CO}_{2} / \mathrm{CH}_{4}$ selectivity values are averaged from two samples.

According to the XRD profile, the Al-containing membrane included a high-purity ZSM-58 phase (Figure 6). Moreover, the membrane thickness tended to increase as the synthesis time increased (Figure 7). Therefore, the $\mathrm{CO}_{2}$ permeance of the Al-containing ZSM-58 membrane decreased as a function of synthesis time because (Figure 8). We measured the $\mathrm{CH}_{4}$ permeance of non-calcined ZSM- 58 membranes in order to evaluate its denseness immediately after hydrothermal synthesis. The growth of zeolite crystals and the decrease in $\mathrm{CH}_{4}$ permeance of non-calcined ZSM- 58 membrane were promoted with the increase in synthesis time. These results suggest that for the low-MTI and - $\mathrm{KOH}$ compositions, such as $\mathrm{C} 5$, the zeolite layer densification was promoted by the growth of zeolite crystals on the alumina substrate. This is demonstrated by the tendency of the $\mathrm{CO}_{2} / \mathrm{CH}_{4}$ selectivity of Al-containing ZSM-58 membranes to increase as a function of synthesis time. The $\mathrm{CO}_{2}$ permeance of M4 was slightly lower than those of M1 and M2 due to dense zeolite layer. However, the dense zeolite layer of M4 caused very low $\mathrm{CH}_{4}$ permeance; therefore, $\mathrm{M} 4$ had the highest $\mathrm{CO}_{2} / \mathrm{CH}_{4}$ selectivity among the results, as presented in Table 2. Therefore, a dense Al-containing ZSM-58 membrane with few defects was prepared after a long growing time in the calcined RTP and CTC process, which showed high $\mathrm{CO}_{2}$ permeance and $\mathrm{CO}_{2} / \mathrm{CH}_{4}$ selectivity.

\subsection{Membrane Structure of Al-Containing ZSM-58 Membranes}

Figure 9 shows the SEM and EDS results of the Al-containing ZSM-58 membrane (M4); the green and red mapping in the EDS mapping indicate Si and Al, respectively. The EDS analysis was performed on the surface layer of the alumina support; this confirmed that almost all synthesized zeolite crystals were on the surface layer of the alumina support. The Si / Al molar ratio of gel composition of ZSM- 58 zeolite was 70, and ZSM-58 zeolite on the support mainly comprised Si. Thus, the Si and $\mathrm{Al}$ in EDS mapping correspond to the ZSM-58 zeolite and alumina support, respectively. 


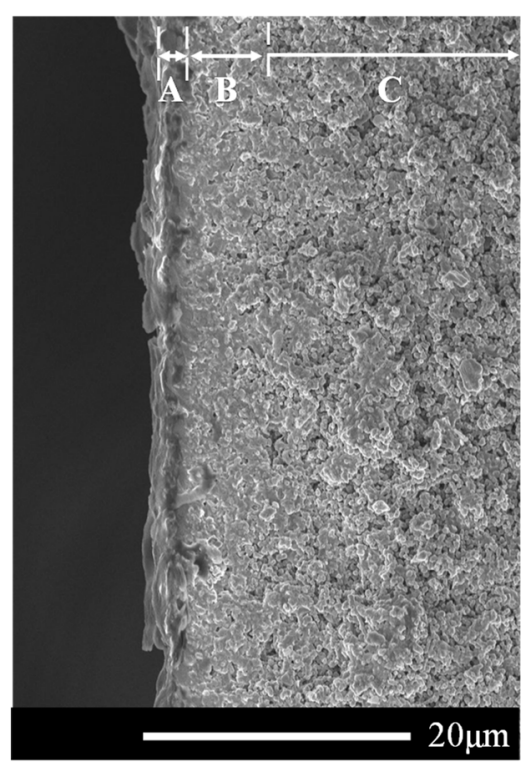

(a)

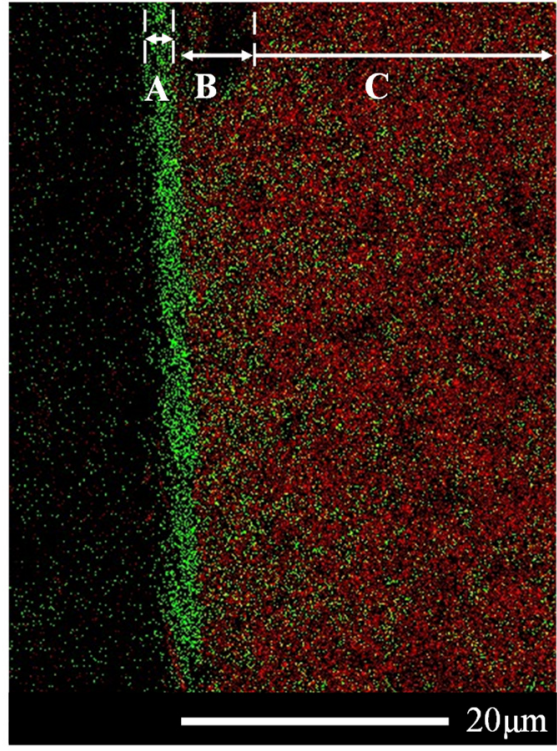

(b)

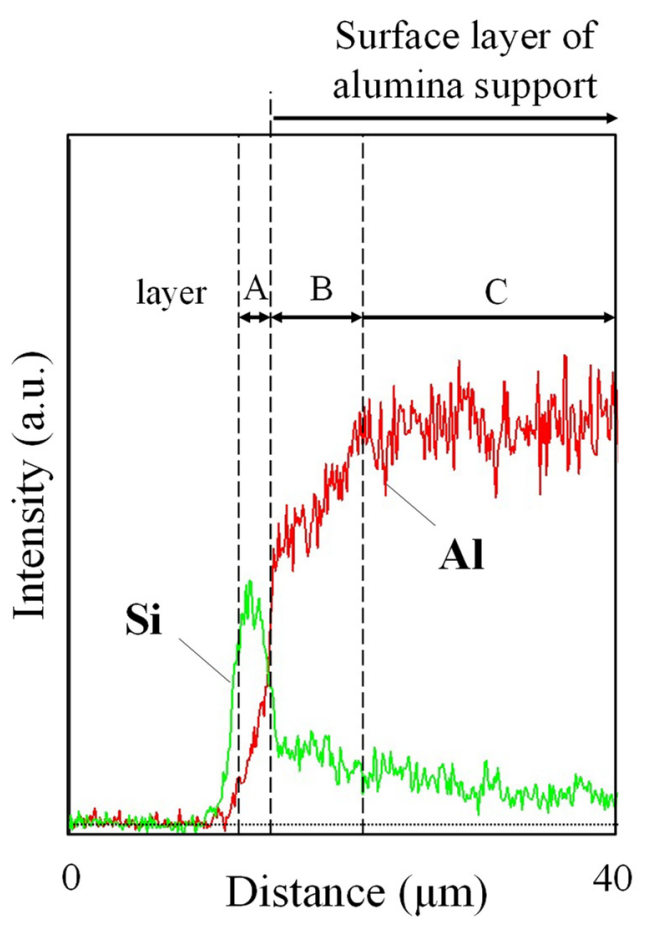

(c)

Figure 9. SEM image (a), element mapping (b), and line analysis (c) of the cross-section of the Al-containing ZSM-58 membrane (M4). Si and $\mathrm{Al}$ are indicated by green and red, respectively.

The structure of the M4 membrane was classified into layers A, B, and C using line analysis. Layer A comprised only the ZSM-58 zeolite layer due to a few $\mathrm{Al}$ intensities. The thickness of layer A was approximately $2 \mu \mathrm{m}$, and the SEM image of layer A confirmed that ZSM-58 crystals were synthesized outside the alumina support. Moreover, because $\mathrm{Si}$ mapping was present in the alumina support, the ZSM- 58 zeolite was widely synthesized in the alumina surface layer. Layer B had a dense zeolite/alumina composite layer with a thickness of approximately $6 \mu \mathrm{m}$, because the Si intensity was constant and Al intensity gently increased. It was confirmed by SEM that the ZSM-58 zeolite in layer B was densely synthesized in porous alumina. By contrast, layer $\mathrm{C}$ had a low $\mathrm{Si} / \mathrm{Al}$ intensity ratio, and vacancies in the alumina support were observed via SEM. Therefore, the gas permeation resistance was larger in layer $B$ than in layer $C$, and layer $C$ did not contribute to gas separation.

The DD3R membrane calcined by the ozone detemplate had approximately 1340 barrer of $\mathrm{CO}_{2}$ permeability $\left(\mathrm{CO}_{2}\right.$ permeance, $3 \times 10^{-7} \mathrm{~mol} / \mathrm{m}^{2} / \mathrm{s} / \mathrm{Pa}$; thickness, $\left.1.5 \mu \mathrm{m}\right)$ [1]; it was considered that the $\mathrm{CO}_{2}$ permeability of the ZSM- 58 membrane was similar to that of the DD3R membrane because ZSM-58 had the same crystal structure as DD3R. M4 was approximately 1900 barrer of the $\mathrm{CO}_{2}$ permeability calculated by using the thicknesses of layer $\mathrm{A}$ and $\mathrm{B}(8 \mu \mathrm{m})$, and it had higher $\mathrm{CO}_{2}$ permeability than the DD3R membrane calcined by the ozone detemplate because molecular MTI was almost removed from the zeolite framework in M4 due to the RTP and CTC processes. Therefore, M4 was configured from the thin outer surface zeolite layer (layer A) and dense zeolite/alumina composite layer (layer $\mathrm{B}$ ), which showed high $\mathrm{CO}_{2}$ permeability after applying RTP and CTC processes.

\subsection{Comparison with All-Silica ZSM-58 Zeolite Membranes}

We compared the $\mathrm{CO}_{2}$ separation performance $\left(\mathrm{CO}_{2}\right.$ permeance; $\mathrm{CO}_{2} / \mathrm{CH}_{4}$ selectivity) of all-silica ZSM- 58 membranes by employing various calcination methods in order to verify the effect of RTP treatments on Al-containing ZSM-58 membrane. Table 3 shows the $\mathrm{CO}_{2} / \mathrm{CH}_{4}$ separation performance of all-silica ZSM-58 membranes (M5 and M6) with 
different calcination methods. M5 and M6 were prepared from a gel composition of $\mathrm{MTI} / \mathrm{KOH} / \mathrm{SiO}_{2} / \mathrm{H}_{2} \mathrm{O}=$ 0.1:0.1:1:52 at $413 \mathrm{~K}$ for $48 \mathrm{~h}$, based on our previous study [4]. Notably, $\mathrm{KOH}$ was used to synthesize all-silica ZSM-58 membranes in order to eliminate the effect of an alkali source, unlike in our previous procedure. Figure 10 shows the SEM images of M1 and M5. The weight loss after calcination indicates the removal rate of the template in the zeolite framework and was calculated by using the following equation:

$$
\text { Weight loss }(\%)=\left(1-\frac{W_{\text {mem,cal }}-W_{\text {support }}}{W_{\text {mem }}-W_{\text {support }}}\right) \times 100
$$

where $W_{\text {mem }}, W_{\text {mem,cal }}$, and $W_{\text {support }}(\mathrm{g})$ are the weights of the as-fabricated membrane, membrane after calcination, and $\alpha$-alumina support, respectively. The ZSM- 58 zeolite contained six cages with eight-membered windows per unit cell, and this unit cell comprised $\mathrm{Si}_{120-} \mathrm{Al}_{X} \mathrm{O}_{240}$. The theoretical weight loss is approximately $11.5 \%$ if the MTI molecule were to be completely removed from the zeolite pore, assuming that the cage with an eight-membered window contains one MTI molecule.

Table 3. Equimolar $\mathrm{CO}_{2} / \mathrm{CH}_{4}$ mixture separation performances of all-silica ZSM-58 zeolite membranes under a total feed pressure of $1.1 \mathrm{MPa}$ at room temperature.

\begin{tabular}{|c|c|c|c|c|c|c|c|c|}
\hline \multirow[b]{2}{*}{ No. } & \multirow[b]{2}{*}{$\begin{array}{l}\text { Calcination } \\
\text { Method }\end{array}$} & \multirow[b]{2}{*}{ Si/Al } & \multirow[b]{2}{*}{$\begin{array}{c}\text { Thickness } \\
(\mu \mathrm{m})\end{array}$} & \multirow[b]{2}{*}{$\begin{array}{l}\text { Weight } \\
\text { Loss (\%) }\end{array}$} & \multirow{2}{*}{$\begin{array}{c}\mathrm{CH}_{4} \text { Permeance of } \\
\text { Noncalcined Membrane } \\
\left(\times 10^{-10} \mathrm{~mol} / \mathrm{m}^{2} / \mathrm{s} / \mathrm{Pa}\right)\end{array}$} & \multicolumn{2}{|c|}{ Permeance $\left(\mathrm{mol} / \mathrm{s} / \mathrm{m}^{2} / \mathrm{Pa}\right)$} & \multirow[b]{2}{*}{$\begin{array}{c}\mathrm{CO}_{2} / \mathrm{CH}_{4} \\
\text { Selectivity }\end{array}$} \\
\hline & & & & & & $\begin{array}{l}\times 10^{-8} \\
\mathrm{PCO}_{2}\end{array}$ & $\begin{array}{l}\times 10^{-10} \\
\mathrm{PCH}_{4}\end{array}$ & \\
\hline M5 & $\begin{array}{c}\text { RTP + } \\
\text { CTC }\end{array}$ & $\infty$ & 3.3 & 11 & 0.3 & 13 & 520 & 2.5 \\
\hline M6 & Ozone & $\infty$ & 3.4 & 6.6 & 6.3 & 8.0 & 5.5 & 150 \\
\hline
\end{tabular}

${ }^{*} \mathrm{CH}_{4}$ permeance was measured before calcination.

M5 and M6 had a dense ZSM-58 membrane with low $\mathrm{CH}_{4}$ permeance before calcination. However, the $\mathrm{CH}_{4}$ permeance of $\mathrm{M} 5$ was increased following the RTP and CTC processes. As shown Table 2, M5 had higher $\mathrm{CH}_{4}$ permeance and lower $\mathrm{CO}_{2} / \mathrm{CH}_{4}$ selectivity than the Al-containing ZSM-58 membrane with a similar membrane thickness (M1). This indicates that, for the all-silica ZSM-58 membrane, the RTP treatment did not exhibit crack suppression effects. RTP strengthens grain boundaries because of the condensation of surface silanol groups ( $\mathrm{Si}-\mathrm{OH})$ [15]. However, it was reported by Wang et al. that RTP had no crack suppression effects on all-silica DDR membranes because the all-silica zeolite membrane has few surface silanols [1]. The Al-containing ZSM-58 membrane (M1) had many surface silanol groups compared to the all-silica ZSM-58 membrane (M5); therefore, the formation of cracks appeared to be suppressed by applying the RTP treatment.
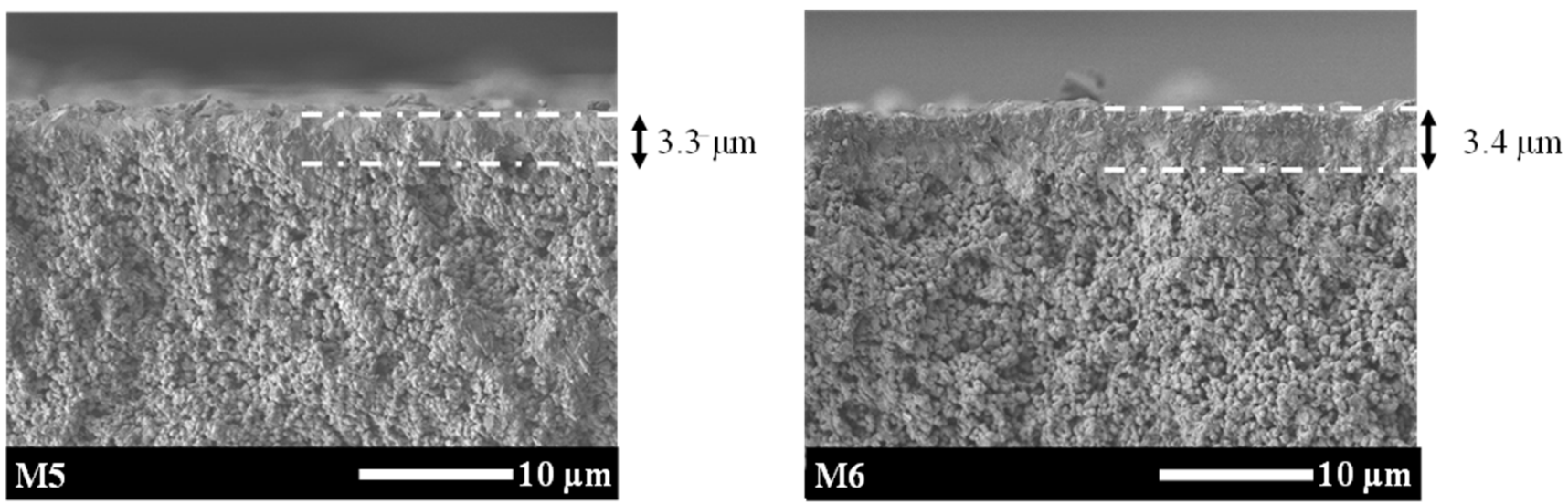

Figure 10. SEM of the cross-sections of all-silica ZSM-58 zeolite membranes M5 and M6. The arrows indicate the thickness of the zeolite membrane. 
Moreover, an all-silica ZSM-58 membrane with improved $\mathrm{CO}_{2} / \mathrm{CH}_{4}$ separation performance could be prepared using the ozone detemplate method [4]. Crack generation was suppressed because the ozone detemplate method could remove the template molecule from zeolite at a lower temperature than the CTC method. M6 was calcined without cracks by the ozone detemplate method, and its $\mathrm{CO}_{2} / \mathrm{CH}_{4}$ separation selectivity showed a similar value to that of M4. Although the all-silica membrane had a thinner zeolite layer than the Al-containing ZSM-58 membrane (Figure 10), M6 had a $\mathrm{CO}_{2}$ permeance similar to that of M4. Therefore, the $\mathrm{CO}_{2}$ permeability of $\mathrm{M} 6$ was approximately 790 barrer, which was lower than that of M4 (1900 barrer). This was due to insufficient detemplating from the zeolite framework. The M6 membrane could only decrease in weight by about half of the theoretical values, and the ozone detemplate method could not completely remove the template, unlike thermal calcination [12]. The molecular template in the zeolite framework inhibited the diffusion of molecular $\mathrm{CO}_{2}$ into zeolite pores. On the other hand, all samples (M1-4) in Table 2 had a weight loss of approximately 11\%; RTP and CTC processes could eliminate molecular MTI from the zeolite framework.

In summary, RTP treatment could be utilized to prepare Al-containing zeolite membranes without cracks. In addition, almost all molecular templates could be eliminated from the zeolite framework during the CTC process. Therefore, RTP treatment is effective for preparing Al-containing ZSM-58 membranes with high $\mathrm{CO}_{2}$ permeability and $\mathrm{CO}_{2} / \mathrm{CH}_{4}$ selectivity.

\subsection{Characteristics of ZSM-58 Crystals and Membranes with Different Si/Al Molar Ratios and Calcination Conditions by FTIR}

It is considered that the RTP treatment suppressed cracks in the Al-containing zeolite membrane with a high silanol concentration due to surface silanol condensation (Figure 11a) [1,15]. Therefore, we investigated the effect of RTP treatment by monitoring the silanol concentration of ZSM-58 zeolite crystals and membranes with various $\mathrm{Si} / \mathrm{Al}$ molar ratios as the calcination process progressed. The surface silanol concentration was measured by FTIR, as per a report on silica membranes [22-24], and the silanol concentration was evaluated from the peak area ratio of surface silanol groups ( $\mathrm{Si}-\mathrm{OH})$ to siloxane (Si-O-Si) (Figure 11b). The surface silanol group (Si-OH) was attributed to peaks at $960 \mathrm{~cm}^{-1}$, and the siloxane (Si-O-Si) groups were attributed to peaks at 1060, 1100, 1170, and $1210 \mathrm{~cm}^{-1}$ [23]. The FTIR spectra were deconvoluted by using the Fityk program based on Gaussian peaks [25], and the area of each peak was measured.

Figure 12 shows the FTIR spectra of the ZSM- 58 zeolite crystals with various Si / Al molar ratios between 500 and $1500 \mathrm{~cm}^{-1}$. Table 4 shows the synthesis conditions and peak area ratios of $\mathrm{Si}-\mathrm{O}-\mathrm{H} / \mathrm{Si}-\mathrm{O}-\mathrm{Si}$ of the $\mathrm{ZSM}-58$ crystals with different $\mathrm{Si} / \mathrm{Al}$ molar ratios. The silanol concentration of the ZSM-58 crystal before RTP treatment increased proportionally to the $\mathrm{Al}$ concentration (Table 4). However, the silanol concentrations of ZSM-58 crystals were decreased by RTP treatment, and the decrease in silanol concentration indicated the formation of siloxane bridges due the condensation of surface silanol groups. Figure 13 shows the degree of diminution of the peak area ratio of $\mathrm{Si}-\mathrm{OH} / \mathrm{Si}-\mathrm{O}-\mathrm{Si}$ on the ZSM-58 crystal before and after RTP treatment. The ZSM- 58 zeolite crystals with lower Si / Al molar ratios $(\mathrm{Si} / \mathrm{Al}=40$ and 70$)$ had greater decreases in the peak area ratio of $\mathrm{Si}-\mathrm{OH} / \mathrm{Si}-\mathrm{O}-\mathrm{Si}$ than that of the high-silica ZSM-58 zeolite crystals $(\mathrm{Si} / \mathrm{Al}=300$ and $\infty)$. This result suggests that more siloxane bridges were formed by silanol condensation on Al-rich ZSM- 58 zeolite during RTP treatment. 
(a)

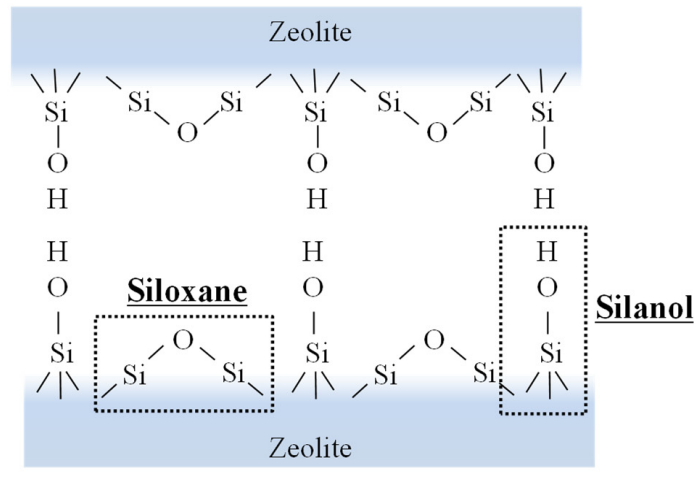

$\underline{\text { RTP treatment }}$

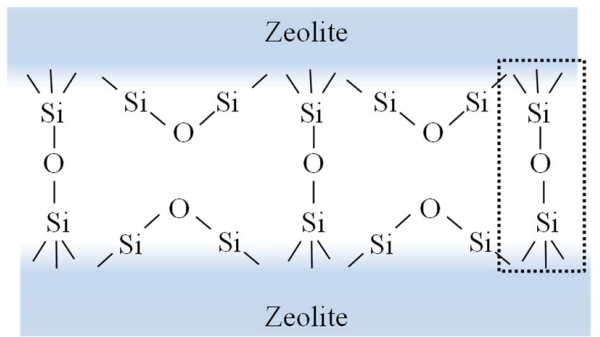

(b)

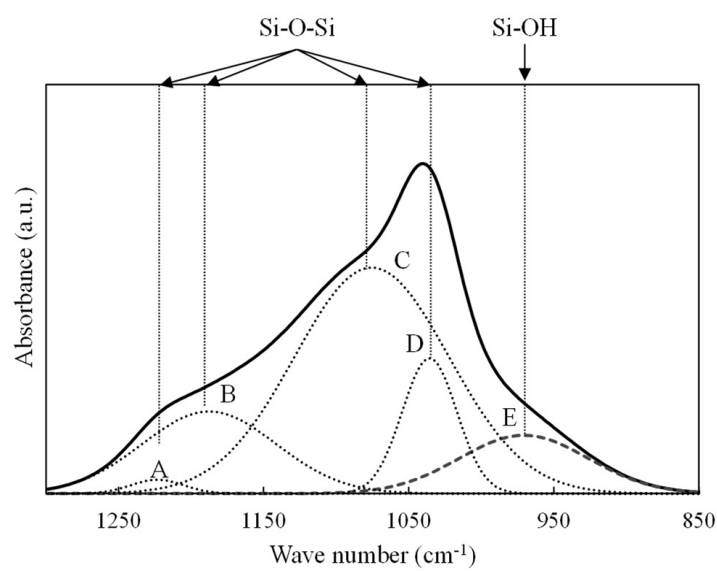

- Silanol (Si-OH): approximately $960 \mathrm{~cm}^{-1}$

- Siloxane (Si-O-Si) approximately $1040,1080,1170$ and $1200 \mathrm{~cm}^{-1}$

Peak area ratio $(\mathrm{Si}-\mathrm{OH} / \mathrm{Si}-\mathrm{O}-\mathrm{Si})=\frac{\mathrm{E}}{\mathrm{A}+\mathrm{B}+\mathrm{C}+\mathrm{D}}$

\section{Formation of siloxane bridge in grain boundaries.}

Figure 11. (a) Schematic formation of silanol bridges by silanol condensation, and (b) FTIR spectrum with deconvoluted peak components using the Gaussian line shape $[1,15,23]$.

Table 4. Synthesis conditions and peak area ratios of silanol concentrations of ZSM-58 crystals with different $\mathrm{Si} / \mathrm{Al}$ molar ratios with the measured FTIR spectra.

\begin{tabular}{cccccccc}
\hline \multirow{2}{*}{$\mathbf{S i} / \mathbf{A l}$} & $\mathbf{M T I} / \mathbf{S i O}_{\mathbf{2}}$ & $\mathbf{K O H} / \mathbf{S i O}_{\mathbf{2}}$ & $\mathbf{H}_{\mathbf{2}} \mathbf{O} / \mathbf{S i O}_{\mathbf{2}}$ & Time (h) & $\begin{array}{c}\text { Temperature } \\
\text { (K) }\end{array}$ & & \multicolumn{2}{c}{ Peak Area Ratio (Si-OH/Si-O-Si) } \\
\cline { 7 - 9 } & & & & 96 & 433 & 0.082 & 0.010 \\
70 & 0.25 & 0.33 & 40 & 120 & 413 & 0.083 & 0.022 \\
70 & 0.05 & 0.05 & 52 & 72 & 413 & 0.071 & 0.040 \\
$\infty 00$ & 0.1 & 0.1 & 52 & 48 & 413 & 0.065 & 0.034 \\
\hline
\end{tabular}

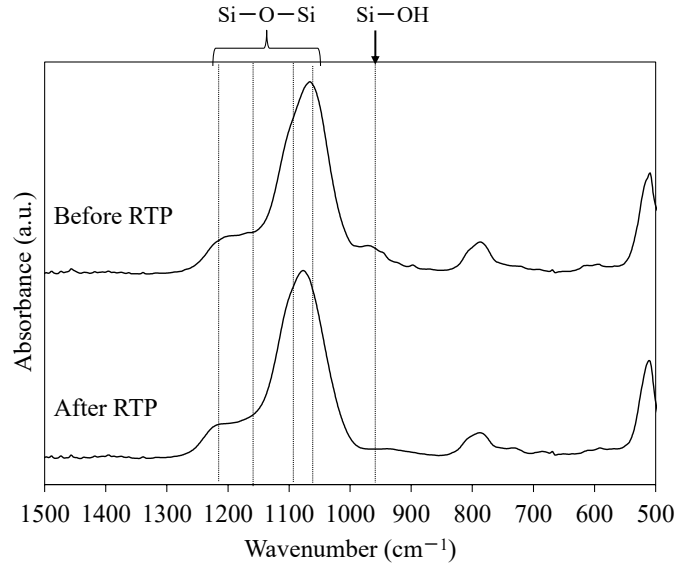

(a) $\mathrm{Si} / \mathrm{Al}=40$

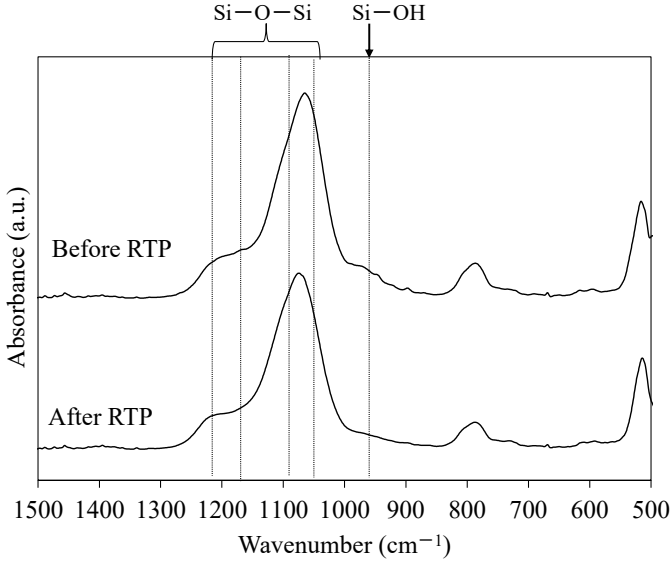

(b) $\mathrm{Si} / \mathrm{Al}=70$

Figure 12. Cont. 


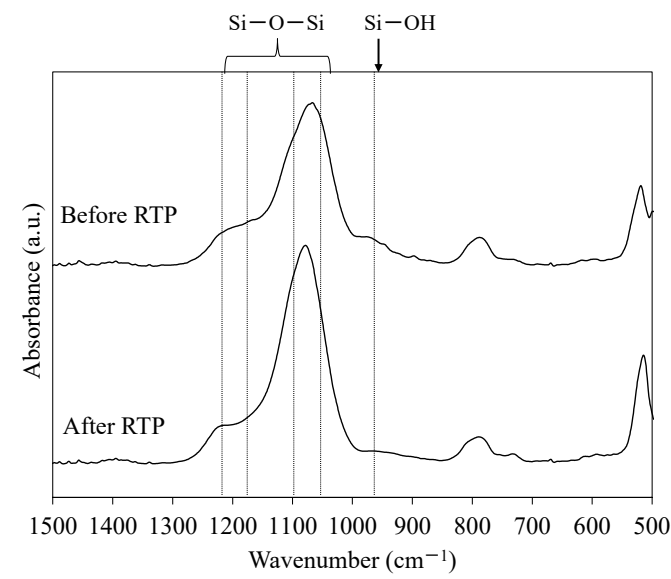

(c) $\mathrm{Si} / \mathrm{Al}=300$

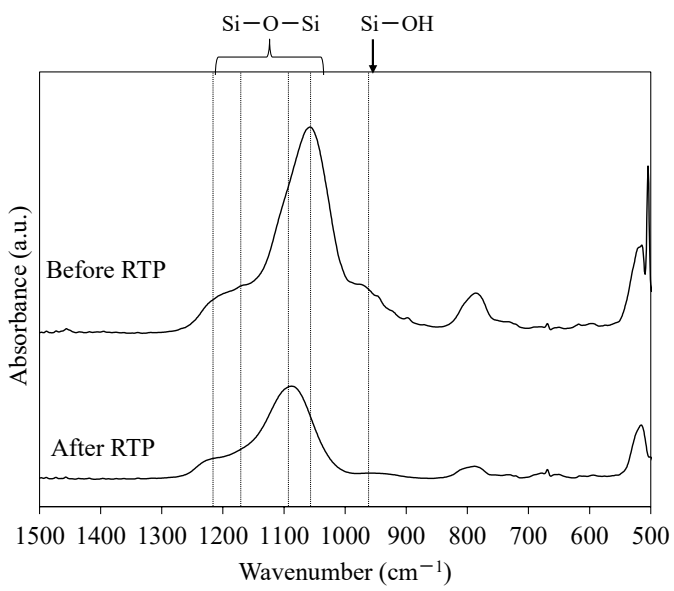

(d) $\mathrm{Si} / \mathrm{Al}=\infty$

Figure 12. FTIR spectra (500 to $1500 \mathrm{~cm}^{-1}$ ) of the as-made ZSM-58 zeolite crystals with different Si/Al molar ratios (a-d) before and after RTP treatment.

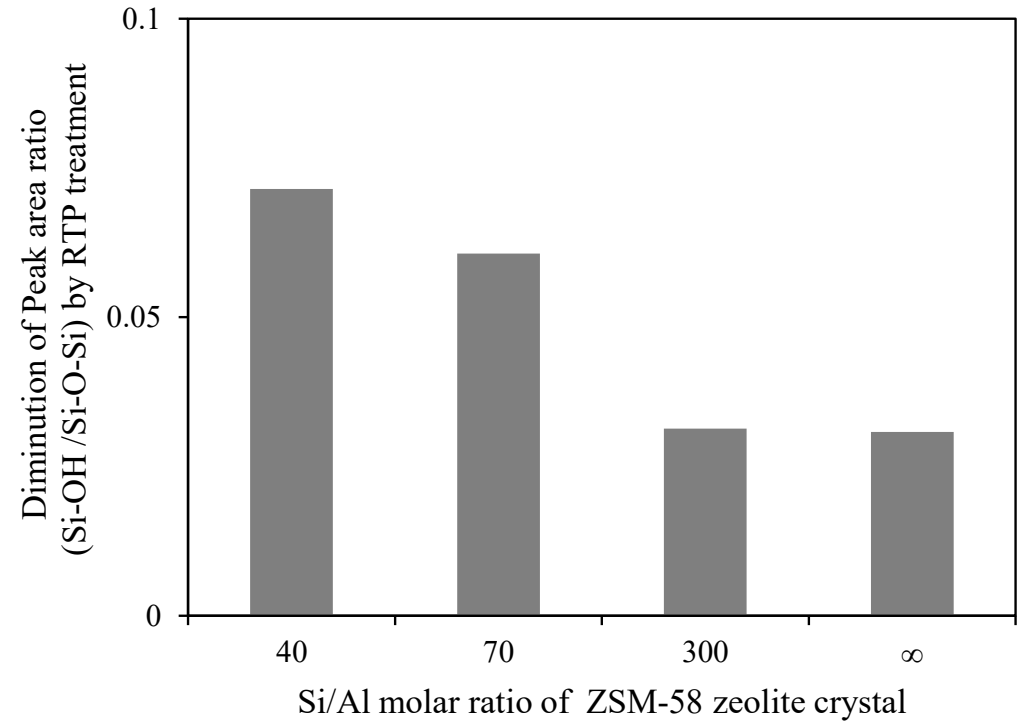

Figure 13. Diminution of peak area ratio $(\mathrm{Si}-\mathrm{O}-\mathrm{H} / \mathrm{Si}-\mathrm{O}-\mathrm{Si})$ on ZSM-58 crystals with different $\mathrm{Si} / \mathrm{Al}$ molar ratios after RTP treatment.

Next, we directly confirmed surface silanol group condensation from the FTIR spectrum of the ZSM-58 membrane. The FTIR spectrum of the ZSM-58 zeolite membrane was obtained by ATR [26]. Table 5 shows the peak area ratios of $\mathrm{Si}-\mathrm{OH} / \mathrm{Si}-\mathrm{O}-\mathrm{Si}$ for all-silica and Al-containing ZSM-58 zeolite membranes. These membranes were prepared by using the same conditions as in M4 and M5. Figure 14 shows the FTIR spectra of the Al-containing and all-silica ZSM-58 zeolite membranes before and after RTP treatment. Figure 15 shows the decrease in peak area ratio of $\mathrm{Si}-\mathrm{OH} / \mathrm{Si}-\mathrm{O}-\mathrm{Si}$ on the ZSM-58 membrane by RTP treatment. As with the ZSM-58 crystal, the Al-containing ZSM-58 zeolite membrane before RTP treatment had a higher silanol concentration and a greater decline in the peak area ratio of Si-OH/Si-O-Si after RTP treatment than the all-silica ZSM-58 zeolite membrane. These results suggest that the Al-containing membrane improves thermal stress resistance during the CTC process because siloxane bridges were formed from surface silanol groups on the zeolite membrane with high Al concentrations due to RTP treatment. In summary, we confirmed that a ZSM-58 membrane with high thermal resistance was formed because bonding between zeolite crystals was enhanced by forming siloxane bridges due to silanol condensation. 
Table 5. Peak area ratios of the silanol concentration of the ZSM-58 membrane with different Si / Al molar ratios measured by FTIR.

\begin{tabular}{ccc}
\hline \multirow{2}{*}{ Si/Al } & \multicolumn{2}{c}{ Peak Area Ratio (Si-OH/Si-O-Si) } \\
\cline { 2 - 3 } & Before RTP & After RTP \\
\hline$\infty$ & 0.149 & 0.086 \\
70 & 0.162 & 0.069 \\
\hline
\end{tabular}

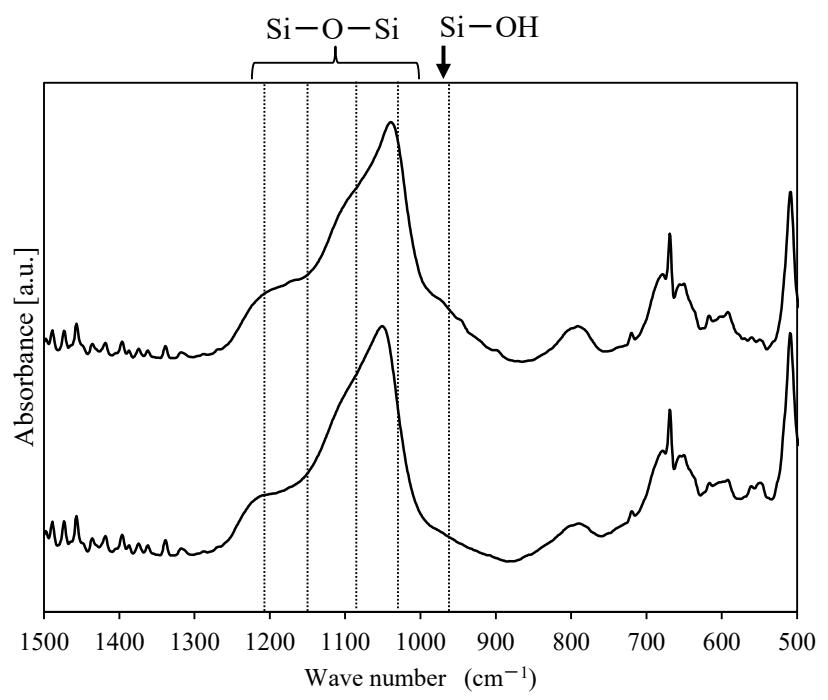

(a) $\mathrm{Si} / \mathrm{Al}=70$

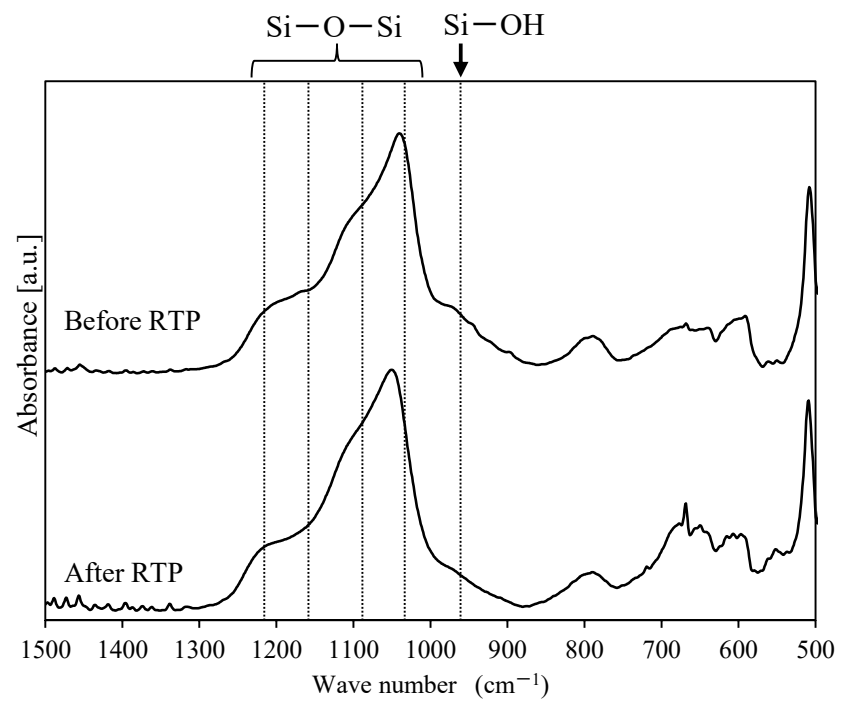

(b) $\mathrm{Si} / \mathrm{Al}=\infty$

Figure 14. FTIR spectra (500 to $1500 \mathrm{~cm}^{-1}$ ) of ZSM-58 zeolite membranes with Si/ Al ratios of 70 (a) and $\infty$ (b) prepared using the ATR method before and after RTP treatment.

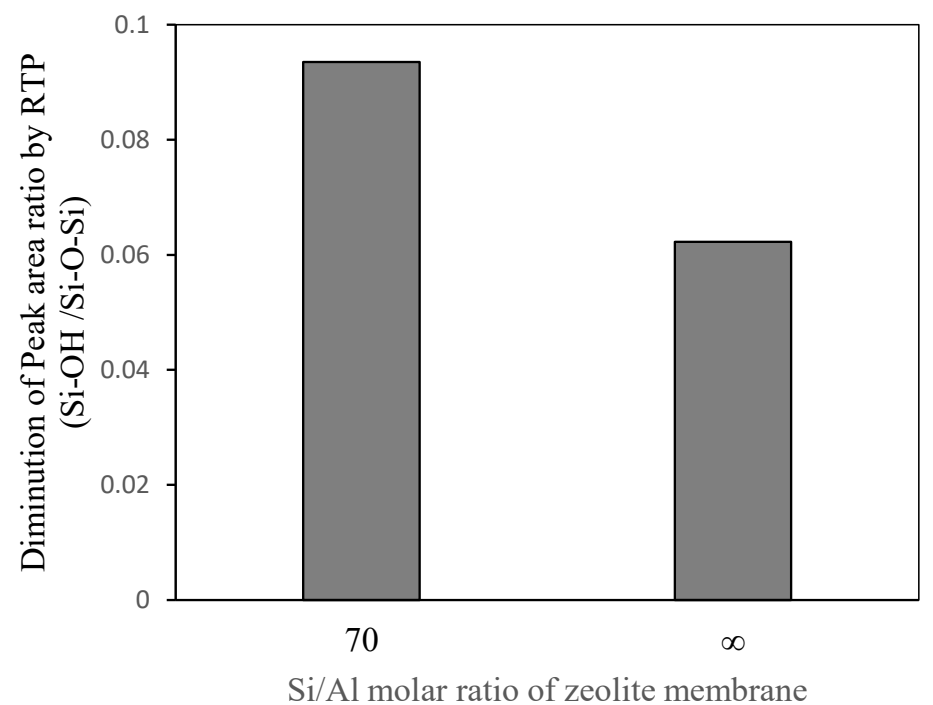

Figure 15. Diminution of the peak area ratio $(\mathrm{Si}-\mathrm{O}-\mathrm{H} / \mathrm{Si}-\mathrm{O}-\mathrm{Si})$ of ZSM-58 membranes with different $\mathrm{Si} / \mathrm{Al}$ molar ratios after RTP treatment.

\section{Conclusions}

We studied the synthesis conditions for an Al-containing ZSM-58 zeolite membrane using RTP treatment. For the preparation of Al-containing and all-silica ZSM-58 zeolite membranes, RTP treatment was applied before the CTC process; as a result, the suppression effect of formed cracks was confirmed only in the Al-containing ZSM-58 zeolite membrane. The CTC method with RTP treatment completely removed the template and enhanced 
the $\mathrm{CO}_{2}$ permeance and $\mathrm{CO}_{2} / \mathrm{CH}_{4}$ selectivity of the Al-containing ZSM- 58 membrane. The all-silica ZSM-58 membrane without cracks was prepared by only using the ozone detemplate method. In particular, the Al-containing ZSM-58 zeolite membrane with high $\mathrm{CO}_{2} / \mathrm{CH}_{4}$ separation selectivity was prepared by slow crystallization in solution, with a gel composition of MTI: $\mathrm{KOH}: \mathrm{SiO}_{2}: \mathrm{H}_{2} \mathrm{O}=0.05: 0.05: 1: 52$ at $413 \mathrm{~K}$ for $120 \mathrm{~h}$.

The effect of RTP was confirmed by the FTIR analysis of ZSM- 58 zeolite crystals and membranes prepared using different calcination methods. The surface silanol concentration increased with $\mathrm{Al}$ concentration in the zeolite, and siloxane bond formation on the ZSM-58 zeolite with a low $\mathrm{Si} / \mathrm{Al}$ molar ratio occurred due to more surface silanol condensation following RTP. These trends were observed on both ZSM- 58 zeolite crystals and membranes. Therefore, we demonstrated the effectiveness of RTP treatments in the preparation of Alcontaining ZSM-58 membranes by monitoring the silanol concentrations of ZSM-58 zeolite membranes with different $\mathrm{Si} / \mathrm{Al}$ molar ratios as the calcination process progressed.

In summary, RTP treatment was the most effective approach to achieve efficient template removal and crack-free Al-containing ZSM-58 membranes, and we have presented a new method in this paper for the preparation of DDR-type zeolite membranes without cracks by applying RTP treatments to Al-containing ZSM-58 zeolite.

Author Contributions: E.H.: date curation, formal analysis, investigation, methodology, validation, visualization, and writing - original draft preparation. S.H.: conceptualization, funding acquisition, project administration, resources, supervision, and writing-review and editing. All authors have read and agreed to the published version of the manuscript.

Funding: This work was supported by JSPS KAKENHI (grant number JP15K12227).

Institutional Review Board Statement: Not applicable.

Informed Consent Statement: Not applicable.

Data Availability Statement: Data available upon request.

Acknowledgments: The FTIR spectroscopy measurements were performed at the Nagaoka University of Technology Analysis and Instrumentation Center. We thank Nagaoka University of Technology Analysis and Instrumentation Center for the use of facilities and equipment.

Conflicts of Interest: The authors declare no conflict of interest. The authors declare that they have no known competing financial interests or personal relationships that could have appeared to influence the work reported in this paper.

$\begin{array}{ll}\text { Abbreviations } \\ \text { MTI } & \text { Methyltropinium iodide } \\ \text { SDA } & \text { Structure-directing agent } \\ \text { XRD } & \text { X-ray diffraction } \\ \text { SEM } & \text { Scanning electron microscopy } \\ \text { EDS } & \text { Energy-dispersive X-ray spectrometry } \\ \text { XRF } & \text { X-ray fluorescence spectroscopy } \\ \text { FTIR } & \text { Fourier transform infrared } \\ \text { ATR } & \text { Attenuated total reflectance } \\ \text { RTP } & \text { Rapid thermal processing } \\ \text { CTC } & \text { Conventional thermal calcination. }\end{array}$

\section{References}

1. Wang, M.; Bai, L.; Li, M.; Gao, L.; Wang, M.; Rao, P.; Zhang, Y. Ultrafast synthesis of thin all-silica DDR zeolite membranes by microwave heating. J. Membr. Sci. 2019, 572, 567-579. [CrossRef]

2. Yang, S.; Cao, Z.; Arvanitis, A.; Sun, X.; Xu, Z.; Dong, J. DDR-type zeolite membrane synthesis, modification and gas permea-tion studies. J. Membr. Sci. 2016, 505, 194-204. [CrossRef]

3. Hayakawa, E.; Himeno, S. Synthesis of a DDR-type zeolite membrane by using dilute solutions of various alkali metal salts. Sep. Purif. Technol. 2019, 218, 89-96. [CrossRef] 
4. Hayakawa, E.; Himeno, S. Synthesis of all-silica ZSM-58 zeolite membranes for separation of $\mathrm{CO}_{2} / \mathrm{CH}_{4}$ and $\mathrm{CO}_{2} / \mathrm{N}_{2}$ gas mixtures. Microporous Mesoporous Mater. 2020, 291, 109695. [CrossRef]

5. Himeno, S.; Tomita, T.; Suzuki, K.; Nakayama, K.; Yajima, K.; Yoshida, S. Synthesis and permeation properties of a DDR-type zeolite membrane for separation of CO2/CH4 gaseous mixtures. Ind. Eng. Chem. Res. 2007, 46, 6989-6997. [CrossRef]

6. Tomita, T.; Nakayama, K.; Sakai, H. Gas separation characteristics of DDR type zeolite membrane. Microporous Mesoporous Mater. 2004, 68, 71-75. [CrossRef]

7. Xu, N.; Liu, Z.; Zhang, Y.; Qiu, H.; Kong, L.; Tang, X.; Meng, D.; Kong, X.; Wang, M.; Zhang, Y. Fast synthesis of thin all-silica DDR zeolite membranes by co-template strategy. Microporous Mesoporous Mater. 2020, 298, 110091. [CrossRef]

8. Wang, L.; Zhang, C.; Gao, X.; Peng, L.; Jiang, J.; Gu, X. Preparation of defect-free DDR zeolite membranes by eliminating tem-plate with ozone at low temperature. J. Membr. Sci. 2017, 539, 152-160. [CrossRef]

9. Dong, J.; Lin, Y.S.; Hu, M.; Peascoe, R.A.; Payzant, E.A. Template-removal-associated microstructural development of po-rousceramic-supported MFI zeolite membranes. Microporous Mesoporous Mater. 2000, 34, 241-253. [CrossRef]

10. Kosinov, N.; Auffret, C.; Sripathi, V.G.P.; Gücüyener, C.; Gascon, J.; Kapteijn, F.; Hensen, E.J.M. Influence of support mor-phology on the detemplation and permeation of ZSM-5 and SSZ-13 zeolite membranes. Microporous Mesoporous Mater. 2014, 197, 268-277. [CrossRef]

11. Park, S.H.; Grosse-Kunstleve, R.W.; Graetsch, H.; Gies, H. The thermal expansion of the zeolites MFI, AFI, DOH, DDR, and MTN in their calcined and as synthesized forms. Stud. Surf. Sci. Catal. 1997, 105, 1989-1994.

12. Kuhn, J.; Gascon, J.; Gross, J.; Kapteijn, F. Detemplation of DDR type zeolites by ozonication. Microporous Mesoporous Mater. 2009, 120, 12-18. [CrossRef]

13. Heng, S.; Lau, P.P.S.; Yeung, K.L.; Djafer, M.; Schrotter, J.C. Low-temperature ozone treatment for organic template removal from zeolite membrane. J. Membr. Sci. 2004, 243, 69-78. [CrossRef]

14. Tang, H.; Bai, L.; Wang, M.; Zhang, Y.; Li, M.; Wang, M.; Kong, L.; Xu, N.; Zhang, Y.; Rao, P. Fast synthesis of thin high silica SSZ-13 zeolite membrane using oil-bath heating. Int. J. Hydrogen Energy 2019, 44, 23107-23119. [CrossRef]

15. Choi, J.; Jeong, H.K.; Snyder, M.A.; Stoeger, J.A.; Masel, R.I.; Tsapatsis, M. Grain boundary defect elimination in a zeolite membrane by rapid thermal processing. Science 2009, 325, 590-593. [CrossRef] [PubMed]

16. Stoeger, J.A.; Choi, J.; Tsapatsis, M. Rapid thermal processing and separation performance of columnar MFI membranes on porous stainless steel tubes. Energy Environ. Sci. 2011, 4, 3479-3486. [CrossRef]

17. Chang, N.; Tang, H.; Bai, L.; Zhang, Y.; Zeng, G. Optimized rapid thermal processing for the template removal of SAPO-34 ze-olite membranes. J. Membr. Sci. 2018, 552, 13-21. [CrossRef]

18. Kim, J.; Jang, E.; Hong, S.; Kim, D.; Kim, E.; Ricther, H.; Simon, A.; Choi, N.; Korelskiy, D.; Fouladvand, S.; et al. Micro-structural control of a SSZ-13 zeolite film via rapid thermal processing. J. Membr. Sci. 2019, 591, 117342. [CrossRef]

19. Karge, H.G.; Weitkamp, J. Molecular Sieves; Springer Nature: Basingstoke, UK, 1998; Volume 1, pp. 67-72.

20. Hadjiivanov, K. Identification and characterization of surface hydroxyl groups by infrared spectroscopy. Adv. Catal. 2014, 57, 99-318.

21. Gucuyener, C.; van den Bergh, J.; Joaristi, A.M.; Magusin, P.C.M.M.; Hensen, E.J.M.; Gascon, J.; Kapteijn, F. Facile synthesis of the DD3R zeolite: Performance in the adsorptive separation of buta-1,3-diene and but-2-ene isomers. J. Mater. Chem. 2011, 21, 18386. [CrossRef]

22. Rahman, S.K.; Rampun, E.L.A.; Rahma, A.; Elma, M. Deconvolution of carbon silica templated thin film us-ing ES40 and P123via rapid thermal processing method. Mater. Today: Proc. 2020, 31, 75-78.

23. Wang, S.; Wang, D.K.; Motuzas, J.; Smart, S.; da Costa, J.C.D. Rapid thermal treatment of interlayer-free ethyl silicate 40 derived membranes for desalination. J. Membr. Sci. 2016, 516, 94-103. [CrossRef]

24. Elma, M.; Wang, D.K.; Yacou, C.; da Costa, J.C.D. Interlayer-free P123 carbonised template silica membranes for desalina-tion with reduced salt concentration polarization. J. Membr. Sci. 2015, 475, 376-383. [CrossRef]

25. Wojdyr, M. Fityk: A general-purpose peak fitting program. J. Appl. Crystallogr. 2010, 43, 1126-1128. [CrossRef]

26. Kyotani, T.; Sato, K.; Mizuno, T.; Kakui, S.; Aizawa, M.; Saito, J.; Ikeda, S.; Ichikawa, S.; Nakane, T. Characterization of zeolite NaA membrane by FTIR-ATR and its application to the rapid evaluation of dehydration performance. Anal. Sci. 2005, 21, 321-325. [CrossRef] 